Portland State University

PDXScholar

$11-8-2016$

\title{
Effects of Antibiotic Mixtures across Marine Intertidal Trophic Levels: Examining Environmentally- Relevant Contaminant Concentrations
}

Jaclyn Rebecca Teixeira

Portland State University

Follow this and additional works at: https://pdxscholar.library.pdx.edu/open_access_etds

Part of the Environmental Sciences Commons, Other Pharmacy and Pharmaceutical Sciences Commons, and the Pharmacology, Toxicology and Environmental Health Commons Let us know how access to this document benefits you.

\section{Recommended Citation}

Teixeira, Jaclyn Rebecca, "Effects of Antibiotic Mixtures across Marine Intertidal Trophic Levels: Examining Environmentally-Relevant Contaminant Concentrations" (2016). Dissertations and Theses. Paper 3372.

https://doi.org/10.15760/etd.5263

This Thesis is brought to you for free and open access. It has been accepted for inclusion in Dissertations and Theses by an authorized administrator of PDXScholar. Please contact us if we can make this document more accessible: pdxscholar@pdx.edu. 
Effects of Antibiotic Mixtures across Marine Intertidal Trophic Levels:

Examining Environmentally-Relevant Contaminant Concentrations

\author{
by \\ Jaclyn Rebecca Teixeira \\ A thesis submitted in partial fulfillment of the \\ requirements for the degree of \\ Master of Science \\ in \\ Environmental Science and Management
}

Thesis Committee:

Elise F. Granek, Chair

Angela Strecker

Elena Nilsen

Portland State University

2016 


\begin{abstract}
Approximately $48 \%$ of Americans use prescription drugs within each 30-day period, and there are signs this trend is increasing. Although many studies track pharmaceuticals' fates in contaminating waterways, only fairly recent efforts have examined the potential impacts of these drugs on non-target organisms. The antibiotics sulfamethoxazole and trimethoprim, often prescribed together to treat bacterial infections, have been detected worldwide in marine and estuarine environments at concentrations up to $700-800 \mathrm{ng} / \mathrm{L}$ each. Toxic effects of these drugs have been identified in freshwater organisms, with synergistic effects observed in short-term studies of mixtures of the two; however, little research has examined possible sub-lethal and longer-term effects of antibiotics in environmentally-relevant mixture concentrations on marine organisms. I examined the long-term effects of mixtures of these two antibiotics in species of a marine system: marine microalgal species, and marine mussels, to determine whether the levels currently present in waterways affect organism health and reproduction.

Microalgal species may be among the most sensitive organisms to pharmaceutical contaminants based on ecotoxicity research. I exposed three species of marine microalgae (Isochrysis galbana, Chaetoceros neogracile, and Nannochloropsis oculata) to environmentally-relevant mixtures of sulfamethoxazole and trimethoprim and examined their three-week growth rates. I found that for each species, the antibiotic treatments significantly suppressed algal growth. Specifically, I found that sulfamethoxazole was a driving factor in suppression of C. neogracile and I. galbana growth, while N. oculata responded more sensitively to a broader range of treatment mixture levels, which also
\end{abstract}


included trimethoprim-only treatment groups and mixtures. These results on marine microalgae address critical data gaps, and identify the impacts of pharmaceuticals on marine primary producers, which could have direct ecosystem implications to higher trophic levels.

Antibiotic pharmaceuticals can also affect marine mussel health, based on previous study of sub-cellular endpoints. I hypothesized that the important benthic foundational species, the Mytilus californianus mussel, would be significantly impacted by long-term 12-week exposure to environmentally-relevant concentrations and mixtures of sulfamethoxazole and trimethoprim. Specifically, I measured growth rate, feeding rate, condition index, and gonando-somatic index as indicators of whole-organism and reproductive health. Sulfamethoxazole concentrations, in particular, and trimethoprim to a lesser extent, suppressed mussel growth and significantly affected condition index and gonandosomatic index over time. The results of this study offer an understanding of how an intertidal system responds to chronic presence of antibiotic mixtures in the water, and a more complete picture of the environmental consequences of pharmaceutical contaminants released into marine ecosystems at ever-growing rates. 


\section{ACKNOWLEDGEMENTS}

It is with deep gratitude and appreciation that I would like to acknowledge and thank several individuals who have made my research possible. I would like to thank those who selected me for Edward D. and Olive C. Bushby Scholarships, as well as an Anchor QEA scholarship, as these provided the funding for my laboratory experiments investigating emerging contaminants. I greatly value my experience working with and learning from my adviser, Dr. Elise Granek, and am grateful for her guidance in developing and executing this project, with further expert guidance from thesis committee members Dr. Angela Strecker, and Dr. Elena Nilsen.

My time at Portland State as a researcher, student, and teaching assistant was positively impacted by a number of people. Joey Peters and Meredith Holgerson provided invaluable assistance in study design for my project, Cameron Siegal helped construct lab apparatuses, and Kale Clauson provided help in many instances of lab problem-solving. Undergraduate assistance in the lab by Rheanna Williams, Michael Young, and Dylan Dayrit is greatly appreciated, and I'm grateful for early input from Blaine Schoolfield and Kimberley Preston at the Hatfield Marine Science Center, Oregon State University. I would also like to thank the Portland State University Environmental Science and Management faculty for providing funding through rewarding Teaching Assistantships for two years, from which I gained just as much as the students, if not more. Members of the ESM community made this experience truly gratifying and enriching, and in particular I would like to acknowledge the following: Ashley Vizek, Maddee Rubenson, Erin Looper, Casey Lewis, Amy Ehrhart, Joey Peters, Inez Lawson, Amelia Johnson, 
Matt DeAngelo, Whitney McClees, Tim Elder, Dr. Jennifer Morse, Dr. Yangdong Pan, Dr. John Reuter, and Dr. Catherine de Rivera.

Lastly, I would like to thank my wonderful family: my parents, Louis and Kathleen, my brother Jacob, and my partner Cam Siegal, for their endless support and encouragement during this graduate school journey and beyond, and the loving memory of my sister, Jordyn, from whom I continually gain inspiration to seize each day with daring spirit and joy. 


\section{TABLE OF CONTENTS}

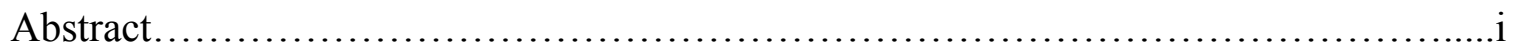

Acknowledgments.........................................................

List of Tables............................................................ vii

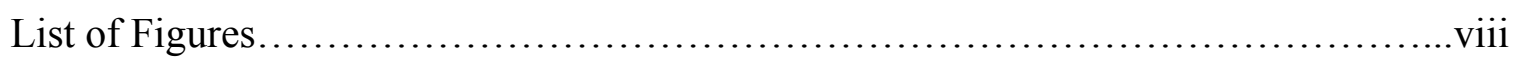

Chapter 1: Introduction.....................................................

Chapter 2: Effects of antibiotics mixtures at environmentally-relevant concentrations on marine microalgae

Introduction. .................................................6

Methods.......................................................... 10

Algal Cultures............................................10

Antibiotics....................................................10

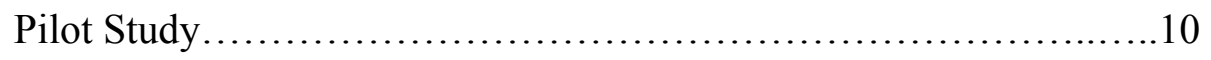

Experimental Design........................................11

Statistical Analysis........................................... 12

Results.........................................................13

Discussion.........................................................

Chapter 3: Environmentally-relevant concentrations of antibiotic mixtures and marine mussel growth, feeding, and reproduction health

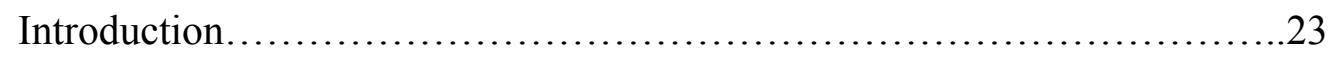

Methods........................................................ 27

Study Organisms and Acclimation Conditions....................27

Experimental Design......................................28 
Antibiotics.

Endpoints.............................................. 30

Mussel Growth......................................30

Feeding Rates.............................................. 31

Body condition: Gonado-somatic Index \& Condition Index...32

Data Analysis..............................................32

Results.............................................................

Mussel Growth...............................................33

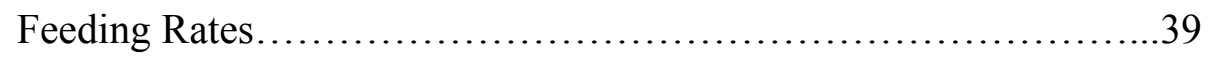

Body condition: Gonado-somatic Index \& Condition Index...........39

Discussion........................................................ 42

Chapter 4: Conclusions.................................................47

Literature Cited........................................................... 51 


\section{LIST OF TABLES}

Table 2.1. Antibiotic mixture treatment concentrations (high and low values are based off of worldwide occurrence data range averages). The 9 treatment levels (grey) are comprised of control (0), low, and high levels in every combination. For each treatment, $\mathrm{n}=9 . \mathrm{SMX}=$ sulfamethoxazole, TRI $=$ trimethoprim, with bold indicating SMX levels.

Table 2.2. Repeated-measures ANOVA results of algal growth for three algal species. Significant factors and P-values $<0.05$ are shown in bold.

Table 3.1. Antibiotic mixture treatment concentrations (high and low values are based off of worldwide occurrence data range averages). The 9 treatment levels (grey) are comprised of control (0), low, and high levels in every combination. For each treatment, $\mathrm{n}=9$. $\mathrm{SMX}=$ sulfamethoxazole, $\mathrm{TRI}=$ trimethoprim, with bold indicating SMX levels.

Table 3.2. Endpoints measured in test mussels in response to treatment of antibiotics SMX and TRI mixtures.

Table 3.3. Repeated-measures ANOVA results for growth factors. Response variables were log-transformed (volume) or square-root transformed (L, H, W, Mass). SMX or TRI refers to antibiotic concentration levels; significant factors $(p<0.05)$ are shown in bold.

Table 3.4. Repeated measures ANOVA results for mean tank body condition indices (CI and GSI) and algal clearance rates, including $2^{\text {nd }}$, and $3^{\text {rd }}$ order interactions. Response variables were log-transformed. SMX or TRI refers to antibiotic concentrations; Significant factors and $p$-values $<0.05$ are shown in bold. 


\section{LIST OF FIGURES}

Figure 1.1 Conceptual model of knowns, questions, and hypotheses framing this thesis investigating long-term effects of pharmaceutical contaminants on marine intertidal species.

Figure 2.1. Results of the growth phase of algal cell density treatment averages for A) $I$. galbana, B) C. neogracile and C) $N$. oculata, averaged by antibiotic mixture treatment levels, and standardized by Day 0 concentrations. For each treatment, $\mathrm{n}=9$ (except for S2$\mathrm{T} 2$ for I. galbana, where $\mathrm{n}=8$ ). Error bars indicate $\pm \mathrm{SE}$ of the mean.

Figure 2.2. The growth phase of algal cell density for A) I. galbana, B) C. neogracile and C) N. oculata in response to the treatment plan, averaged by the SMX concentrations (neglecting TRI concentrations) and standardized by Day 0 concentrations. For each SMX treatment, $n=27$ (except for $A, S 2: n=26$ ). Error bars indicate $\pm S E$ of the mean.

Figure 3.1. The average percent change in mussel growth parameters of total shell volume (A and B), length (C and D), width ( $\mathrm{E}$ and $\mathrm{F})$, height $(\mathrm{G}$ and $\mathrm{H})$, and mass (I and $\mathrm{J})$ across SMX and TRI treatment groups over the experimental period. Error bars reflect $\pm \mathrm{SE}$ of the mean.

Figure 3.2. The average percent change in mussel growth parameters of total shell volume (A), length (B), width (C), height (D), and mass (E) across all SMX and TRI treatment mixtures over the experimental period. Error bars reflect $\pm \mathrm{SE}$ of the mean.

Figure 3.3. Mean mussel tissue indices at weeks 6 and 12 in response to antibiotic treatments for A) CI by SMX level, B) CI by TRI level, C) GSI by SMX level, D) GSI by TRI level, D) CI by SMX and TRI mixtures and E) GSI by SMX and TRI mixtures. Lowercase letters and asterisks $(*=$ different than control) represent significant differences, $p<0.05$. 


\section{Chapter 1: Introduction}

From 2009-2012, 48.7\% of Americans used prescription drugs within any 30-day period, and data indicate this trend is increasing (Gu et al. 2010, National Center for Health Statistics 2015). Prescription drugs are a profitable and rapidly growing industry in the US, with spending on all prescription drugs totaling \$234.1 billion in 2008 (more than double the amount spent in 1999), and currently estimated at approximately $\$ 300$ billion (Guo 2015, World Health Organization 2016). This figure is expected to grow to \$400 billion within just three years (World Health Organization 2016). Approximately $31 \%$ of Americans use two or more prescription drugs in a given 30-day period, with one in five children, and nine out of 10 elderly people taking drugs during any 30-day period. For antibiotic prescription drugs in particular, four out of five Americans $(80 \%)$ use antibiotics at least once a year (Gu et al. 2010). West Virginia, the state with the highest usage rate of antibiotics, reported 1,222 prescriptions for antibiotics per every 1,000 people during 2007; thus, some Americans are receiving multiple antibiotic prescriptions per year (CDDEP 2011).

These pharmaceuticals, which are widely used in both human and veterinary medicine, find many pathways into the environment (Boxall 2004). Many pharmaceutical compounds are not fully metabolized by the human body, remaining biologically active in waste. In turn, onsite and wastewater treatment plant systems fail to remove all pharmaceuticals before releasing effluent water into the environment. Moreover, improper disposal of expired or unneeded pharmaceuticals, industrial emissions, and agricultural uses (e.g., antibiotic use in aquaculture) also contribute to environmental pollution (Boxall 2004). As a result, a vast array of pharmaceuticals has been detected in 
marine and freshwater organisms, sediments, and waters at high ng/L levels, and even in drinking water, with potential unintended effects on non-target organisms and food webs (Daughton and Ternes 1999). The threat of antibiotic resistance developing due to environmental exposure to antibiotics and antimicrobials has also caused increasing concern regarding the growing resistance of pathogenic bacteria in the environment, and this is a problem that will likely persist and potentially worsen (Kümmerer 2004).

In examining the body of research assessing pharmaceutical effects on aquatic organisms, there are numerous trends in the type of frequently undertaken studies as well as clear data gaps. Trends in this field include freshwater organism-focused studies, assessing acute toxicity of pharmaceuticals at high concentrations (greater than occurrence data concentrations), and employing short-term exposures (on the order of hours to days), with single-drug studies. The identified data gaps represent the contrast of many of these factors: marine organism-focused studies are markedly lacking, and also studies assessing sub-lethal responses to chronic or longer-term exposures (on the order of weeks to months) at lower concentrations (Gaw et al. 2014). Additionally, potential mixture effects of pharmaceuticals have been recognized as vitally important as they more closely simulate real-world exposures than single-drug studies (Christensen et al. 2006). With the ever-fluctuating cocktails of low levels of pharmaceuticals in waterways, systematic mixture studies are needed to parse out unknown synergisms. GonzálezPleiter et al. (2013) found from their tests using antibiotic mixtures on freshwater organisms, "it can be concluded that certain specific combinations may pose a potential ecological risk for aquatic ecosystems with the present environmentally measured concentrations." 
Current lack of management action on behalf of governing bodies in the form of preventative measures to lessen impacts of pharmaceutical contaminants may be due to the fact that the concentrations in which these drugs are detected are often a small fraction of typical prescribed therapeutic doses for humans and animals. Thus, they are deemed a low risk to human health, and the World Health Organization (2016) notes that any form of water safety improvements draws on limited funds and resources that need to be prioritized based on potential negative impacts to human health. The WHO states that the implementation of pharmaceutical removal techniques would be extremely costly and is not currently considered necessary, as there would be a limited human health benefit (WHO 2016). However, this perspective neglects any sort of ecological implications, and perhaps dampens the impetus by policymakers or the pharmaceutical industry to make improved awareness of proper disposal techniques to the public a goal within their influence spheres.

Pharmaceuticals are specifically designed to elicit a biological response at low levels, so even low concentrations could impose negative effects on both target and nontarget organisms. The antibiotics sulfamethoxazole (SMX) and trimethoprim (TRI) are often prescribed together to treat a suite of bacterial infections. In a 5:1 ratio, they comprise the antibiotic drug Bactrim, which is on the World Health Organization's List of Essential Medicines (WHO 2015). Their mode of action is inhibiting synthesis of the bacterial enzyme tetrahydrofolic acid, a folic acid derivative (Boothe 2015); however, they interrupt the synthesis chain at two different points, leading to synergistic effects in combination due to their different target sites (Eguchi et al. 2004). SMX and TRI have been commonly detected worldwide in marine and estuarine environments, at 
concentrations up to $870 \mathrm{ng} / \mathrm{L}$ for trimethoprim, and $765 \mathrm{ng} / \mathrm{L}$ for sulfamethoxazole (Gaw et al. 2014). Toxicity of these drugs has been identified in freshwater organisms, with acute synergistic effects observed in mixtures of the two (Eguchi et al. 2004); however, little research has been conducted examining possible sub-lethal effects on marine organisms with chronic exposure (weeks to months) at environmentally-relevant concentrations.

For my MS research project, I examined effects of these two commonly-detected antibiotics in all mixture combinations including environmentally-relevant high, low and control levels on (1) 3-week marine microalgal growth rates for Isochrysis galbana, Chaetoceros neogracile, and Nannochloropsis oculata and (2) 12-week intertidal marine mussel, Mytilus californianus growth rates, feeding rates, and reproductive and condition indices (Figure 1). In separate simulations using a laboratory temperature/ lightcontrolled tank set-up, I measured these endpoints to parse out independent effects; I also consider potential interactive trophic effects within the food chain. I hypothesize that, based on the known microalgal sensitivities to pharmaceuticals, documented mussel subcellular immuno-sensitivity health responses to antibiotics, and the synergistic nature of SMX and TRI, algal growth over time will be suppressed, and growth and health indicators of marine mussels will be suppressed (Isidori et al. 2005, Guo et al. 2015, Lacaze et al. 2015, Figure 1). An understanding of how a representative intertidal system responds to chronic exposure of SMX and TRI mixtures offers a more complete picture of the environmental consequences antibiotic pharmaceuticals have when released into marine ecosystems at ever-growing rates, and sheds light on the potential for cascading trophic effects. 


\section{Knowns}

People increasingly use pharmaceutical drugs

Drugs find pathways into environment, are found in high $\mathrm{ng} / \mathrm{l}$ concentrations

Lack of studies on long-term effects at low concentrations on marine organisms, esp. mixtures

SMX + TRI behave synergistically as antibiotics

Organisms across taxa have complex relationships with bacteria

Freshwater microalgae: sensitive to pharmaceuticals/antibiotics

Mussels studies - mostly cellular/subcellular responses, indicate immno sensitivity to antibiotics

\section{Questions}

Do environmentally-relevant levels of mixtures of SMX + TRI affect:

(1) 3-week marine microalgal growth/ reproduction rates?

(2) 12-week marine mussel growth, feeding, and reproductive indicators?

\section{Hypotheses}

(1) SMX + TRI treatments will suppress algal growth rates in higher concentrations, esp. in mixtures

(2) SMX + TRI will suppress mussel feeding rates (algal clearance), growth rates \& condition/ gonado-somatic indices, esp. in mixtures

Figure 1.1 Conceptual model of knowns, questions, and hypotheses framing this thesis investigating long-term effects of pharmaceutical contaminants on marine intertidal species. 


\section{Chapter 2: Effects of antibiotics mixtures at environmentally-relevant concentrations on marine microalgae}

\section{Introduction}

Photosynthetic algae are part of the base of the food web in aquatic ecosystems, and population level alterations to these photoautotrophic organisms can result in quickly-realized and severe bottom-up effects at higher trophic levels (Nie et al. 2013). Thus, microalgae are often used as indicators of pollution and water quality (McCormick and Cairns Jr. 1994). Pharmaceuticals, which are widely used in both human and veterinary medicine, follow many documented pathways into the environment and may be significant stressors to organisms (Boxall 2004).

Pharmaceutical compounds are often not fully metabolized by the human body, remaining biologically active in waste. In turn, onsite and wastewater treatment plant systems fail to remove all pharmaceuticals before releasing effluent water into the environment. Moreover, improper disposal of expired or unneeded pharmaceuticals, industrial emissions, and agricultural uses (e.g., antibiotic use in aquaculture) also contribute to environmental pollution (Boxall 2004). As a result, a vast array of pharmaceuticals has been detected in marine and freshwater organisms, sediments, and waters, including drinking water, at concentrations of high $\mathrm{ng} / \mathrm{L}$ with potential unintended effects on non-target organisms and food webs (Daughton and Ternes 1999).

Aquatic studies of pharmaceutical effects on microalgae have focused on acute toxicity of freshwater microalgae, with most experimental tests completed within 96 hours (Halling-Sørensen 2000, Cleuvers 2003, Eguchi et al. 2004, El-Bassat et al. 2012, González-Pleiter et al. 2013). There is a lack of chronic effects studies using 
environmentally-relevant concentrations of drugs. In several studies of pharmaceutical drugs applied to multiple freshwater organisms (such as algae, Daphnia, fish, and amphibians), the drugs exhibited the greatest effects on freshwater microalgae (Isidori et al. 2005, El-Bassat et al. 2012). Isodori et al. (2005) found that out of the six antibiotics studied, most were bioactive at concentrations in the order of $\mu \mathrm{g} / \mathrm{L}$, mainly for freshwater algae, and the drugs were one or two orders of magnitude less active in rotifers and crustaceans. Thus, microalgae may be among the most sensitive aquatic organisms to antibiotics.

Antibiotics target bacteria rather than eukaryotic algae, but these drugs may also cause detrimental effects to algae, as some algal organelles (such as the chloroplast and mitochondria) retain similarities to bacteria in structure and evolutionary origin (Vannini et al. 2011, Guo et al. 2015). Many organisms also have complex interactions with bacteria, and the application of low-levels of antibiotics over the long term may disrupt these interactions, leading to the suppression of population growth rates and potential effects on the availability of algae as a food source for higher trophic levels. Guo et al.'s (2015) review of the pharmaceutical risks to primary producers found that some antibiotics could pose a potential threat to algal species, with blue-green and green algae being particularly sensitive. However, they note many unstudied aspects of pharmaceutical risks, such as pharmaceutical mixture effects on algal species to identify interactive effects, and the need for studies of long-term effects of pharmaceuticals at environmentally-relevant concentrations (Guo et al. 2015).

Pharmaceutical exposure studies on marine organisms are notably lacking (Gaw et al. 2014). In the present study, I examine the growth response of three marine 
microalgal species to treatment at environmentally-relevant levels of antibiotic mixtures of sulfamethoxazole (SMX) and trimethoprim (TRI). Sulfamethoxazole and trimethoprim are often prescribed together to treat a suite of bacterial infections. In a 5:1 ratio, they comprise the antibiotic drug Bactrim, which is on the World Health Organization's List of Essential Medicines (WHO 2015). Their mode of action is inhibiting synthesis of the bacterial enzyme tetrahydrofolic acid, a folic acid derivative (Boothe 2015); however, they interrupt the synthesis chain at two different points, lending to synergistic effects in combination due to their different target sites (Eguchi et al. 2004). Worldwide, SMX and TRI have been commonly detected in marine and estuarine environments at concentrations up to $870 \mathrm{ng} / \mathrm{L}$ for trimethoprim and $765 \mathrm{ng} / \mathrm{L}$ for sulfamethoxazole (Gaw et al. 2014). Toxicity of these drugs has been identified in freshwater organisms, with acute synergistic effects observed in mixtures of the two (Eguchi et al. 2004); however, little research has examined possible chronic exposure (weeks to months) effects on marine microalgae at environmentally-relevant concentrations. These low-level concentrations and antibiotic mixtures more closely mimic real-world exposures.

Isochrysis galbana, Chaetoceros neogracile, and Nannochloropsis oculata are all eukaryotic marine microalgal species commonly cultured for use in rearing marine organisms such as bivalves, shrimp, and fish (Spolaore et al. 2006). Characteristics such as nutritional requirements for the predator, sufficient cell sizes and digestibility of the microalgae, reproduction rate, and reliable and sustainable culturing in standardized commercial growing systems all determine their applicability in the rearing of different marine organisms. Among the three species, N. oculata and C. neogracile are both within Phylum Heterokontophyta, which contains more than 25,000 species (of mostly algae) 
and are thus most closely related evolutionarily. $C$. neogracile is a centric non-chain forming marine diatom, $6-9 \mu \mathrm{m}$ in width and $2-3 \mu \mathrm{m}$ in length, in the class Bacillariophyceae. N. oculata, is in the class Eustigmatophyceae and differs from other related microalgae in that it has chlorophyll a and completely lacks chlorophyll b and c (Simionato et al. 2013). Compared to closely related taxa, N. oculata are smaller, with a diameter of 2 to $3 \mu \mathrm{m}$ and have a simple structure with reduced structural elements (Simionato et al. 2013). I. galbana is in Phylum Haptophyta, which is characterized by a unique organelle, the haptonema. I. galbana is a single-celled marine microalgal species ranging in length from 3-6 $\mu \mathrm{m}$ and is found in a wide geographic range, including in the northeastern Pacific. I. galbana has commonly been used as an indicator species among primary producers in aquatic food chains and ecosystems (Lai et al. 2009). Huang et al. 2014 found the sulfonamide drug, sulfamonomethoxine, exhibited greater toxicity to $I$. galbana than to Daphnia and fish, and concluded that this drug could be a risk to aquatic organisms in waters. These species reproduce asexually by cell division in the presence of proper light and nutrient conditions.

This study tested the hypothesis that exposure to SMX and TRI over the course of several weeks would significantly suppress algal growth due to the sensitivities of microalgae to pharmaceuticals, and that these effects would be more pronounced in mixture treatments, and at higher concentrations, due to the documented synergistic nature of the two drugs. 


\section{Methods}

Algal Cultures

The marine microalgal species, Isochrysis galbana and Chaetoceros neogracile were provided by B. Schoolfield and K. Preston from the Hatfield Marine Science Center, Newport, OR, while Nannochloropsis oculata was purchased from Mercer of Montana, LLC. All three species were cultivated in 33 ppt seawater, prepared by adding synthetic sea salt (Instant Ocean) to deionized water and adjusting the solution to $33 \mathrm{ppt}$; essential Proline F/2 algal nutrients were added (with sodium metasilicate also added in recommended quantities for the diatom C. neogracile) (Price et al. 1989, RebollosoFuentes et al. 2001). Algae were grown at $15 \pm 1{ }^{\circ} \mathrm{C}$ under a $12 \mathrm{hr}$ light/dark illumination cycle with daily gentle shaking utilizing four 32-watt natural full-spectrum bulbs with 2850 lumens each.

\section{Antibiotics}

Sulfamethoxazole and trimethoprim were purchased from Sigma-Aldrich (St. Louis, MO, USA). Stock solutions of each antibiotic were prepared by dissolving the selected antibiotic in deionized water, and concentrations of each antibiotic were then adjusted from each stock solution using serial dilutions, with negligible volumes of 30-34 $\mu l$ added to each experimental jar every 10 days to mimic effluent pulses. The half-life for primary degradation of trimethoprim in waters is estimated to be $>42$ days, and for sulfonamide drugs $>21$ days (Kümmerer 2008).

Pilot study

An exploratory pilot study was performed prior to the full experiment to test the ability of I. galbana to grow in the proposed laboratory set-up, and to test a cell density 
measuring technique involving microscope slide hemocytometers. I determined that the algae did in fact grow steadily in the laboratory over a period of several weeks before populations crashed in the pilot study, but that the lighting was not sufficiently uniform throughout the tank. Also, the cell counts could be assessed via microscope slides, but the time required to perform this counting method was deemed infeasible for this set-up. As a result of this pilot study, I changed the lighting set-up to achieve uniformity throughout the tank, and I explored the use of an automated hemocytometer to perform algal cell counts, which vastly improved feasibility.

\section{Experimental Design}

Algae growth rates over time were measured in response to a treatment plan comprised of control, low, and high SMX and TRI levels in a 3x3 factorial design. High and low antibiotic concentrations were determined based on Gaw et al. (2014) averages of worldwide occurrence data (Table 2.1). For worldwide occurrence data, the high and low ranges of the two drugs were averaged for all reported instances in which both were present to arrive at the test concentrations (Gaw et al. 2014) (Table 2.1). Nine replicate jars of each of the nine treatments were included in the study. Experimental tests were performed using 16-oz glass jars containing $350 \mathrm{ml}$ of seawater, comprised of Instant Ocean with Proline F/2 ${ }^{\mathrm{TM}}$ algal nutrients at manufacturer recommended levels. The algal inocula were taken from homogenized cultures and added to $350 \mathrm{ml}$ of test solution to obtain initial cell densities. The jars were covered with perforated translucent covers to prevent evaporation and contamination, but gas exchange was allowed. The jars were gently shaken once a day. Treatments were randomly distributed within a water bath maintained at $15 \pm 1^{\circ} \mathrm{C}$ and under a $12 \mathrm{hr}$ full spectrum light/dark illumination cycle. 
Cell growth lasted for 12 to 15 days for I. galbana (with counts taken for 19 days), and 21 days for C. neogracile and N. oculata and was measured at 3-day intervals. The cell density of algae was counted by an automated hemocytometer (Beckman Coulter Counter, dual threshold) once every 3 days, for which $100 \mu 1$ of the test medium was extracted from each jar. Growth curves of cell density over time were set up to determine species-specific rates of algal population growth over 20 days.

Table 2.1. Antibiotic mixture treatment concentrations (high and low values are based off of worldwide occurrence data range averages). The 9 treatment levels (grey) are comprised of control (0), low, and high levels in every combination. For each treatment, $\mathrm{n}=9 . \mathrm{SMX}=$ sulfamethoxazole, $\mathrm{TRI}=$ trimethoprim, with bold indicating SMX levels.

\begin{tabular}{|c|c|c|c|c|}
\hline \multicolumn{2}{c|}{} & \multicolumn{3}{c|}{ SMX } \\
\cline { 2 - 5 } \multicolumn{2}{c|}{} & 0 & $7.5 \mathrm{ng} /$ L (Low) & $75 \mathrm{ng} /$ L (High) \\
\hline \multirow{3}{*}{ TRI } & 0 & $0-0$ & Low - 0 & High - 0 \\
\cline { 2 - 5 } & $8.5 \mathrm{ng} /$ L (Low) & $0-$ Low & Low - Low & High - Low \\
\cline { 2 - 6 } & $85 \mathrm{ng} /$ L (High) & 0 - High & Low - High & High - High \\
\hline
\end{tabular}

\section{Statistical analysis}

Algal data were analyzed with R studio software version 0.98 .1062 including the package "ez" to calculate repeated-measures analysis of variance (ANOVA) to analyze differences in each algal species' population growth at sampling days throughout the testing period (R Development Core Team 2008, Lawrence 2015). Treatment categories and sampling date were factors with tanks included as an error term to account for the non-independence between temporal samples. The assumption of sphericity was 
determined for each factor using the Mauchly test and adjusted using Greenhouse-Geisser corrections. Differences in beginning concentrations were accounted for by standardizing to Day 0 concentrations prior to analysis. Population growth rates during the growth phase for each algal species were analyzed. Interaction plots of final algal counts were generated to parse out interactive drug effects when significant. Normality and homogeneity of variances were assessed through graphical inspection of the model residuals, and data were square-root (for C. neogracile and I. galbana) or logtransformed (for N. oculata) to meet these assumptions. Post-hoc significant differences between treatments and controls were measured with a pair-wise Tukey test. Values were considered significantly different at $\mathrm{p}<0.05$.

\section{Results}

Algal cell density grew over time in three species of marine microalgae, but was suppressed at higher levels of SMX for all species (Figure 2.1A-C). Treatments with higher levels of SMX resulted in lower algal cell density over time for C. neogracile and I. galbana and all but one treatment mixture concentration resulted in lower cell densities over time for N. oculata as compared to the control (Figure 2.1, Table 2.2). 


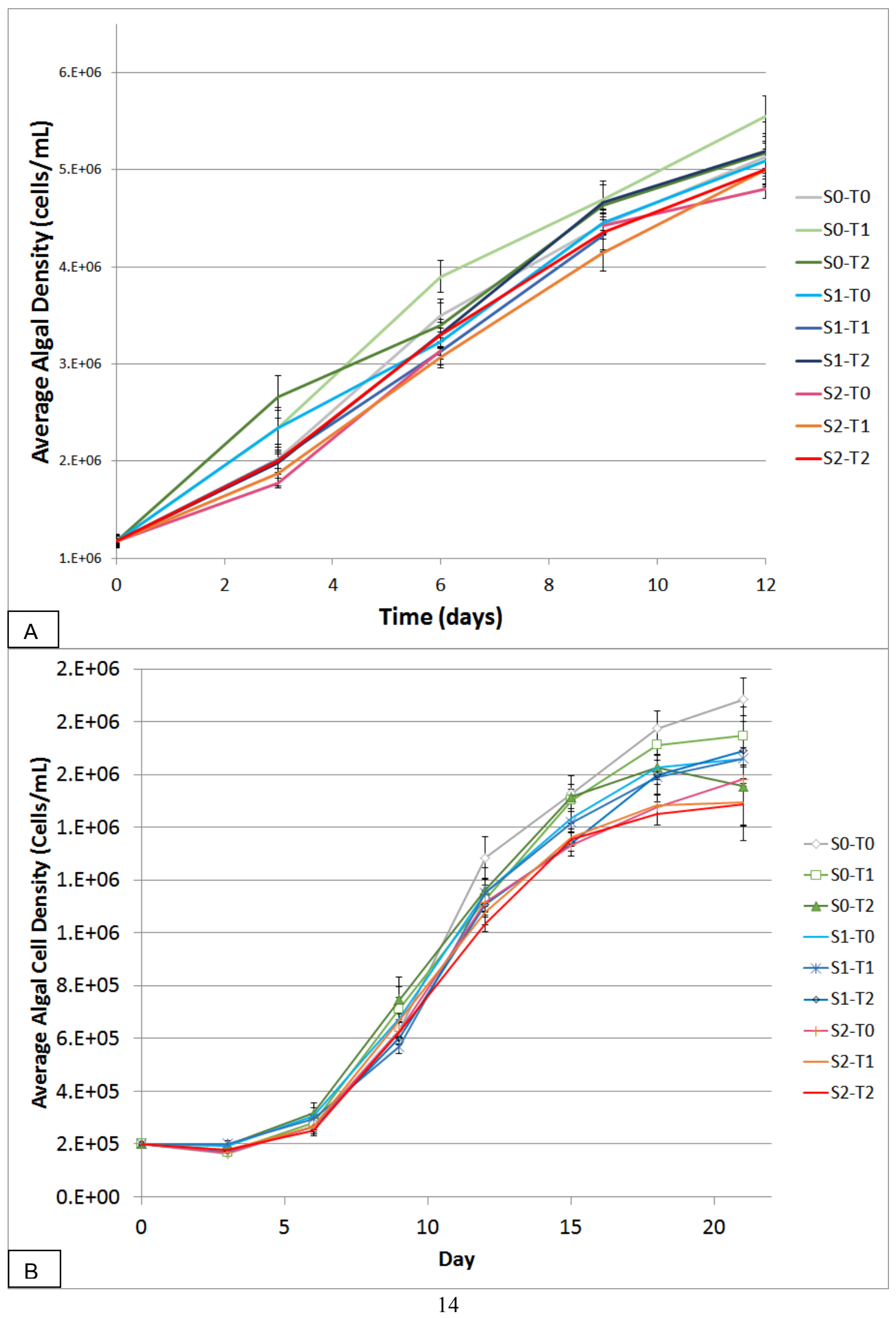




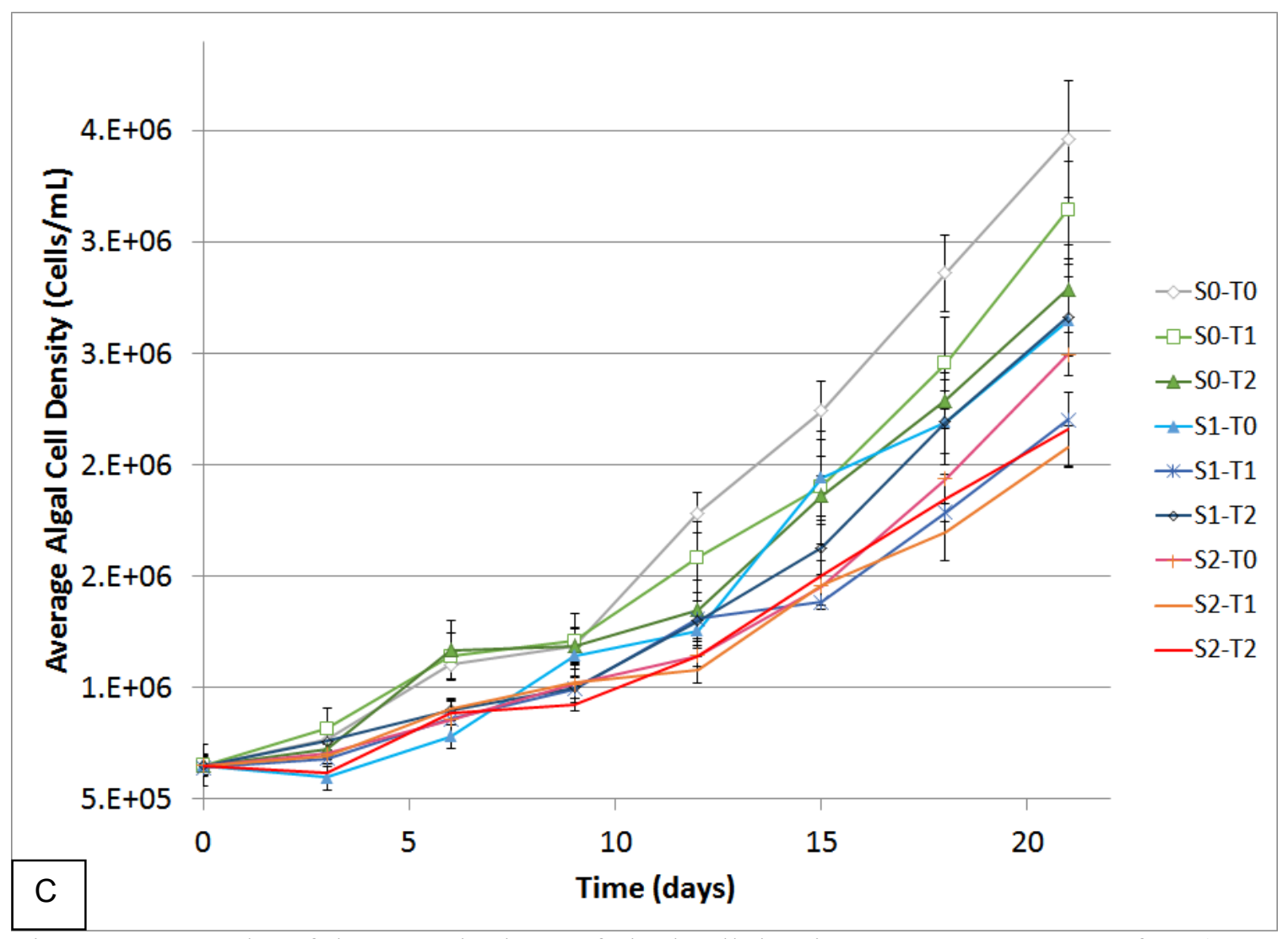

Figure 2.1. Results of the growth phase of algal cell density treatment averages for A) $I$. galbana, B) C. neogracile and C) $N$. oculata, averaged by antibiotic mixture treatment levels, and standardized by Day 0 concentrations. For each treatment, $n=9$ (except for S2$\mathrm{T} 2$ for I. galbana, where $\mathrm{n}=8$ ). Error bars indicate $\pm \mathrm{SE}$ of the mean.

The interaction of SMX level and time had a significant suppressive effect on the growth of all three algal species, while the interactive effect of TRI and time also had a significant suppressive effect on $N$. oculata only (Table 2.2; Figure 2.2). N. oculata responded most sensitively to the treatments with both SMX and TRI treatment levels suppressing algal growth, although there was no significant interactive effect of the two drugs (Table 2.2; Figure 2.1). The interactive effect of SMX and TRI over time was significant for I. galbana, driven by the fact that the S0-T1 treatment growth averages 
were significantly higher than the other treatments, but overall, SMX level was a stronger significant suppressive factor, $\mathrm{F}_{71,284}=5.66, p=0.005$ (Table 2.2).

Table 2.2. Repeated-measures ANOVA results of algal growth for three algal species. Significant factors and P-values $<0.05$ are shown in bold.

\begin{tabular}{|c|c|c|c|c|c|c|}
\hline $\begin{array}{c}\text { Algae } \\
\text { Species }\end{array}$ & Factor & SS & MS & df & $F$ & $p$ \\
\hline \multirow{9}{*}{$\begin{array}{l}\text { Isochrysis } \\
\text { galbana }\end{array}$} & SMX & $6.27 \mathrm{E}+12$ & $3.13 \mathrm{E}+12$ & 2 & 5.66 & 0.005 \\
\hline & TRI & $6.77 \mathrm{E}+11$ & $3.39 \mathrm{E}+11$ & 2 & 0.61 & 0.545 \\
\hline & Sample Date & $8.44 \mathrm{E}+14$ & $4.22 \mathrm{E}+14$ & 2 & 1862.14 & $\begin{array}{l}< \\
\mathbf{0 . 0 0 1}\end{array}$ \\
\hline & TRI*SMX & $1.79 \mathrm{E}+12$ & $4.47 \mathrm{E}+11$ & 4 & 0.81 & 0.524 \\
\hline & SMX * Sample Date & $2.26 \mathrm{E}+12$ & $5.64 \mathrm{E}+11$ & 4 & 2.49 & 0.013 \\
\hline & TRI * Sample Date & $9.23 \mathrm{E}+11$ & $2.31 \mathrm{E}+11$ & 4 & 1.02 & 0.422 \\
\hline & TRI * SMX * Date & $3.47 \mathrm{E}+12$ & $2.17 \mathrm{E}+11$ & 16 & 1.91 & 0.019 \\
\hline & Error among groups & $3.93 \mathrm{E}+13$ & $5.53 \mathrm{E}+11$ & 71 & & \\
\hline & Error within groups & $3.22 \mathrm{E}+13$ & $1.13 \mathrm{E}+11$ & 284 & & \\
\hline \multirow{9}{*}{$\begin{array}{c}\text { Chaetoceros } \\
\text { neogracile }\end{array}$} & SMX & $1.11 \mathrm{E}+14$ & $5.55 \mathrm{E}+13$ & 2 & 7.55 & 0.001 \\
\hline & TRI & $1.43 \mathrm{E}+11$ & $7.15 \mathrm{E}+10$ & 2 & 0.97 & 0.383 \\
\hline & Sample Date & $2.28 \mathrm{E}+14$ & $3.26 \mathrm{E}+13$ & 7 & 1154.16 & $<0.001$ \\
\hline & TRI*SMX & $2.12 \mathrm{E}+14$ & $5.30 \mathrm{E}+13$ & 4 & 0.07 & 0.990 \\
\hline & SMX * Sample Date & $9.38 \mathrm{E}+11$ & $6.70 \mathrm{E}+10$ & 14 & 2.38 & 0.003 \\
\hline & TRI $*$ Sample Date & $2.66 \mathrm{E}+11$ & $1.90 \mathrm{E}+10$ & 14 & 0.67 & 0.800 \\
\hline & TRI $*$ SMX * Date & $5.97 \mathrm{E}+11$ & $2.13 \mathrm{E}+10$ & 28 & 0.76 & 0.814 \\
\hline & Error among groups & $5.27 \mathrm{E}+12$ & $7.43 \mathrm{E}+10$ & 72 & & \\
\hline & Error within groups & $1.42 \mathrm{E}+13$ & $5.00 \mathrm{E}+10$ & 504 & & \\
\hline \multirow{9}{*}{$\begin{array}{c}\text { Nannochloropsis } \\
\text { oculata }\end{array}$} & SMX & $1.79 \mathrm{E}+13$ & $8.93 \mathrm{E}+12$ & 2 & 19.70 & $<0.001$ \\
\hline & TRI & $2.30 \mathrm{E}+12$ & $1.15 \mathrm{E}+12$ & 2 & 2.54 & 0.086 \\
\hline & Sample Date & $2.82 \mathrm{E}+14$ & $4.03 \mathrm{E}+13$ & 7 & 522.69 & $<0.001$ \\
\hline & TRI*SMX & $1.85 \mathrm{E}+12$ & $4.62 \mathrm{E}+11$ & 4 & 1.02 & 0.403 \\
\hline & SMX * Sample Date & $9.50 \mathrm{E}+12$ & $6.79 \mathrm{E}+11$ & 14 & 8.81 & $<0.001$ \\
\hline & TRI * Sample Date & $3.54 \mathrm{E}+12$ & $2.53 \mathrm{E}+11$ & 14 & 3.28 & $<0.001$ \\
\hline & TRI $*$ SMX $*$ Date & $2.85 \mathrm{E}+12$ & $1.02 \mathrm{E}+11$ & 28 & 1.32 & 0.126 \\
\hline & Error among groups & $3.26 \mathrm{E}+13$ & $4.60 \mathrm{E}+11$ & 72 & & \\
\hline & Error within groups & $3.88 \mathrm{E}+13$ & $1.37 \mathrm{E}+11$ & 504 & & \\
\hline
\end{tabular}



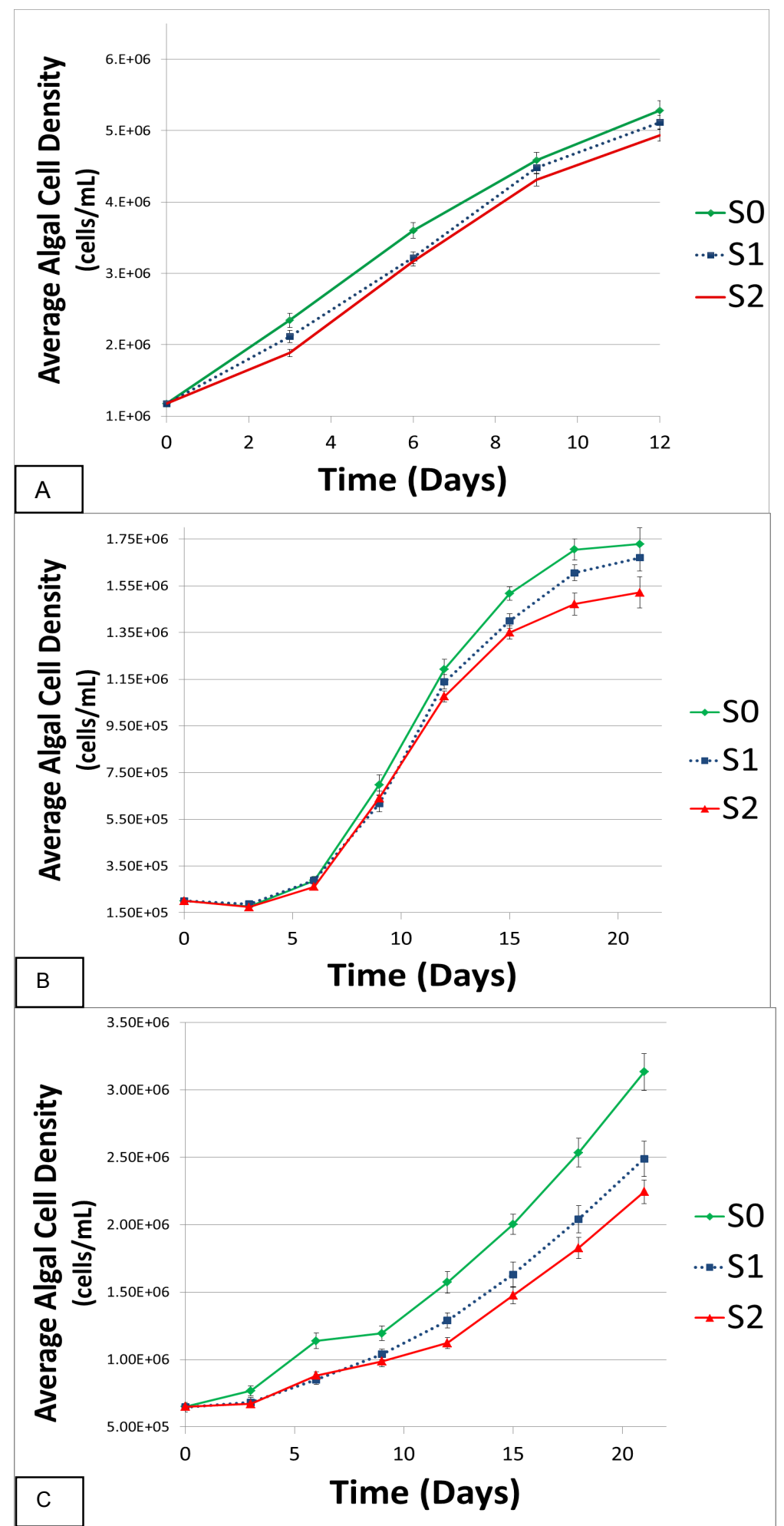

Figure 2.2. The growth phase of algal cell density for A) I. galbana, B) C. neogracile and C) N. oculata in response to the treatment plan, averaged by the SMX concentrations (neglecting TRI concentrations) and standardized by Day 0 concentrations. For each SMX treatment, $n=27$ (except for $A, S 2: n=26$ ). Error bars indicate $\pm S E$ of the mean. 


\section{Discussion}

This study demonstrates that prolonged exposure to environmentally-relevant concentrations of two antibiotics affects algal population growth rates over time. When three species of marine microalgae from two Phyla were monitored over a three week exposure period to better understand how each species responds to mixtures of antibiotics, the compounds and compound combinations that affected algal population growth differed across species. However, SMX concentration was a significant suppressive factor for all three species (with the interaction with time being significant for all). N. oculata was the most sensitive of the three species with TRI also suppressing growth rates and with seven treatment mixture combinations significantly lowering growth. This research builds on previous studies and addresses a prior data gap of identifying chronic exposure effects of antibiotic mixtures at environmentally-relevant levels. By simulating chronic antibiotic mixture exposure in the laboratory, I offer a glimpse into how these emerging contaminants may impair primary producers in marine waters exposed to these drugs, possibly imposing bottom-up effects on marine communities.

SMX concentrations were the main driver of algal reproduction suppression for two of the species, while $N$. oculata, with the most simplified cell structure (Simionato et al. 2013), was significantly affected by both SMX and TRI. Perhaps due to chemical characteristics of the drugs such as solubility or degradation products, or perhaps due to different microalgal species' cellular structure, even species with a similar evolutionary 
lineage can exhibit differential sensitivities to pharmaceutical contaminants within the same class (Guo et al. 2015). Thus, it is important to investigate long-term full factorial testing on mixtures of pharmaceuticals with multiple organisms.

SMX may have had a greater effect on algal growth than TRI due to the potential increased toxicity of the photo-degradation products of SMX in seawater (Trovó et al. 2009b). In studies of the degradation processes and products of both SMX and TRI, it has been found that both chemicals are not readily biodegradable in seawater, but they transform primarily through photo-degradation, which is considerably slowed in saltwater than in freshwater (with a half-life of approximately 42 days for trimethoprim and 21 days for sulfonamide drugs in seawater) (Benotti and Brownawell 2007, 2009, Kümmerer 2008, Larcher and Yargeau 2012). There has been little study of the ecological risks of the photo-degradation products that form, but there is some indication that these products retain the activity of the parent molecule to elicit a toxicological effect on non-target organisms in the environment, which, in some cases, is greater than the toxicity of the parent molecule. Trovó et al. (2009a) found that over the course of the testing period, despite $45 \%$ mineralization in saltwater, toxicity of SMX increased from $16 \%$ to $86 \%$ in Vibrio fischeri bacterium tests, which suggests that the intermediates generated in saltwater are potentially more toxic. Additionally, a separate study on this subject (Trovó et al. 2009b) found that test organisms showed an increase from $60 \%$ to $100 \%$ immobilization over the course of the test period with SMX, with the authors concluding that there was a higher toxicity of the photo-transformation products generated. Trimethoprim photo-degradation studies in saltwater, though limited, indicate "only a 
small increase" in the toxicity on test organisms, with intermediates which were moderately toxic for the organisms tested (Sirtori et al. 2010, Fatta-Kassinos et al. 2011). Toxicity as well as sub-lethal assessments of transformation products must be included in the suite of pharmaceutical contaminant research to more closely simulate environmental conditions.

Marine microalgae possess chloroplast and mitochondrial organelles, retaining similarities to bacteria (the target of antibiotics) in structure and evolutionary origin, but algae and bacteria have also co-existed for more than 200 million years, resulting in complex interactions between them (Vannini et al. 2011, Liu et al. 2012, Guo et al. 2015). An example of this interaction is that bacteria produce and supply vitamin B12 to some diatom species, which is essential for their successful growth (Croft et al. 2005, Guo et al. 2015). A range of antibiotics in environmentally-relevant concentrations can damage bacteria through dissolution of their membranes or inhibition of essential enzymes (Schreiber and Szewzyk 2008, Duggar 2011, Ji et al. 2013). Antibiotics are known to damage bacteria experimentally, and it is likely that similar processes are occurring in the wild to bacteria that supply nutrients to algal species (Guo et al. 2015). Active antibiotics may be indirectly inhibiting algal species by influencing the coexisting nutrient-supply system between marine microalgae and bacteria, which is essential for survival (Croft et al. 2005).

Primary producers are indispensable elements of food webs and nutrient-cycling processes in marine ecosystems; thus impacts of contaminants on microalgae might shift the balance of the community (Kümmerer 2008, Guo et al. 2015). Our findings that 
marine microalgal species may be significantly affected by environmentally-relevant concentrations of antibiotic mixtures serve as a foundation to understand how pharmaceuticals are affecting marine communities through potential trophic interactions. Pharmaceuticals should be considered significant potential stressors to vulnerable aquatic organisms already stressed by other environmental factors such as climate change, ocean acidification, and rising sea level (Waycott et al. 2009). There is little study of the interactive effects of global environmental changes and pharmaceutical toxicity for freshwater organisms and no known research for marine organisms (Kim et al. 2010). Changes in global climate adds a layer of complication in which cell processes ranging from photosynthesis to thermo-regulation are likely to be disrupted, leading to possible combined algal reproductive suppression with contaminants. In a world with changing climate, increasing coastal populations, and rising pharmaceutical use, marine organisms are exposed to an ever-increasing array of pharmaceuticals from different classes and with different target sites, some of which are known to negatively impact aquatic organisms (Boxall 2004, Gaw et al. 2014, Guo et al. 2015)

Many of the effects detected would not have been identified if the study had been run for the typical experimental periods of hours or days. For example, some algal cell density treatment average slopes diverged halfway through the three-week study period (and time-drug interactions were significant for all three species), indicating that longerterm effects of low concentrations of these drugs may be vastly underestimated based on typical shorter period exposure trials. Understanding the extent to which antibiotics in particular and pharmaceuticals in general affect marine organisms over the long-term will 
require investigation across more species, drugs, degradation products, and in combinations. Future research in the field of pharmaceutical contaminants will require focus on these topics to assess basic marine organismal and intra-species effects in order to prevent cumulative potential inter-species ecosystem level effects. 


\section{Chapter 3: Environmentally-relevant concentrations of antibiotic mixtures and marine mussel growth, feeding, and reproduction health}

\section{Introduction}

Pharmaceuticals have many pathways into the environment (through improper disposal of drugs, veterinary use, wastewater treatment plant effluent, and aquaculture use, for example), and have been detected in the natural environment across landscape and waterway types, with many compounds persisting in the environment for months to years (Daughton and Ternes 1999, Richardson et al. 2005, Boxall et al. 2012). The result of these numerous pathways and the worldwide occurrence is that pharmaceuticals have increasingly been recognized as emerging contaminants of concern (Monteiro and Boxall 2009, Boxall et al. 2012). Although commonly detected at relatively low concentrations (ng/L) in the environment compared to medical dosages, pharmaceuticals are designed to elicit biological responses on their target sites, and there exist many critical questions regarding the effects these low concentrations have over the long term on non-target organisms (Boxall et al. 2012). Several decades of research on xenobiotics such as PCBs and DDT has demonstrated the hormone-mimicking, non-monotonic effects on the reproductive systems of organisms due to exposures to those chemicals in the low ng/L range; pharmaceuticals, as biologically-active substances developed with the intention of disrupting specific pathways and processes in humans and organisms, must be similarly intensively investigated for their potential long-term low-level contaminant impacts (Colborn and Clement 1992, Halling-Sørensen et al. 1998, Boxall et al. 2012). 
Recent studies confirm that pharmaceuticals occur widely in marine and coastal environments, but many data gaps in this field exist, including potential risk assessments of marine organisms exposed to these drugs at environmentally-relevant levels (Cleuvers 2003, Gaw et al. 2014). Ecotoxicity studies for pharmaceuticals are commonly performed over a relatively short time span (hours to days), utilizing high concentrations of single drugs at a time, and assessing lethal endpoints (Láng and Köhidai 2012, Gaw et al. 2014). Antibiotics are among the most frequently detected prescription classes (along with betablockers and anti-inflammatory drugs) found in the environment (Láng and Köhidai 2012). The complete environmental risk assessment of antibiotic contaminants on organisms is deficient in several categories such as the lack of chronic, long-term data on low concentrations, sub-lethal endpoints, and utilizing mixture concentrations. In the wild, organisms are not being exposed to one drug at a time; they are exposed to continuously-delivered cocktails of pharmaceuticals at low concentrations that may act synergistically (Glassmeyer et al. 2008). Bridging the knowledge gap between ecotoxicity studies and sub-lethal chronic ecological mixture effects requires a study approach of a different length and scope.

Despite the focus on acute and chronic toxicity to freshwater organisms, there is a lack of understanding of how these pharmaceuticals may impact marine organisms (Gaw et al. 2014). In the present study, I examine whole-organism responses of marine mussels to treatments at environmentally-relevant concentrations of antibiotic mixtures of sulfamethoxazole (SMX) and trimethoprim (TRI). The antibiotics sulfamethoxazole (SMX), and trimethoprim (TRI) are often prescribed together to treat a suite of bacterial infections. In a 5:1 ratio, they comprise the antibiotic drug Bactrim, which is on the 
World Health Organization's List of Essential Medicines (WHO 2015). Their mode of action is inhibiting synthesis of the bacterial enzyme tetrahydrofolic acid, a folic acid derivative (Boothe 2015); however, they interrupt the synthesis chain at two different points, lending to synergistic effects in combination due to their different target sites (Eguchi et al. 2004). Worldwide, SMX and TRI have been commonly detected in marine and estuarine environments, at concentrations up to $870 \mathrm{ng} / \mathrm{L}$ for trimethoprim, and 765 ng/L for sulfamethoxazole (Gaw et al. 2014). Toxicity of these drugs has been identified in freshwater organisms, with acute synergistic effects observed in mixtures of the two (Eguchi et al. 2004); however, little research has examined possible chronic exposure (weeks to months) effects on marine organisms at environmentally-relevant concentrations. These low-level concentrations and antibiotic mixtures, more closely mimic real-world exposures.

The California mussel, Mytilus californianus, is an important benthic foundational species found along the west coast of North America (Suchanek 1992). These invertebrates are efficient filter feeders, able to filter 2-3 liters of water per hour (during which they consume marine microalgae as a food source), and they specialize in living in large aggregations on rocky substrate in the intertidal and subtidal zones (Suchanek 1981). Fabbri and Franzellitti (2015) report that caged mollusks are increasingly used to investigate pharmaceutical occurrence in coastal environments, since their accumulation offers information regarding exposure levels and time. Due to the fact that bivalves are filter-feeding and sessile organisms at the substrate-water interface, they are deemed as effective sentinels for in-situ monitoring of micro-pollutants (Fabbri and Franzellitti 2015). For example, the blue mussel (Mytilus edulis) was found to accumulate five 
pharmaceuticals in a 6-month caging experiment off the Belgian coast (Fabbri and Franzellitti 2015). McEneff et al. (2014) reported the occurrence of 5 pharmaceuticals (including trimethoprim) in marine mussels during a 1-year long caging experiment along the Irish coastline, with most of the five drugs found in mussel tissues also detected in surface waters at average concentrations in the mid to high $\mathrm{ng} / \mathrm{L}$.

The potential toxicity and sub-lethal effects of pharmaceuticals in general and antibiotics in particular on aquatic invertebrates is still poorly understood (Lacaze et al. 2015). For marine organisms, there are a lack of studies on whole-organism sub-lethal effects and a lack of chronic exposure studies using environmentally-relevant pharmaceutical concentrations. Lacaze et al. (2015) showed that antibiotics affect the immune system of the blue mussel, Mytilus edulis, utilizing genotoxic and immunotoxic endpoints. There is a focus in this field on sub-organismal assessment methods, where the effects of pharmaceutical exposure on freshwater and marine bivalves are at the molecular level, such as disturbed enzyme functions, DNA damage, and modulated gene expression (Franzellitti et al. 2013, Gonzalez-Rey and Bebianno 2013, Lacaze et al. 2015). There are also cellular level studies, with assessments of increased oxidative stress, cytotoxicity and immunotoxicity (Gust et al. 2012, Tsiaka et al. 2013, Lacaze et al. 2015).

Many organisms have complex interactions with bacteria (which play a role in digestion across taxonomic groups (Eckburg et al. 2005), and it has been demonstrated that pharmaceutical target sites in humans may have counterparts which could be present in invertebrates, and possibly affect comparable pathways (Christen et al. 2010). Building on this, I examined the response of marine mussels in the form of growth and mass, algal 
clearance rates, and condition and reproductive indices to environmentally-relevant mixtures of the antibiotics sulfamethoxazole (SMX) and trimethoprim (TRI). I hypothesize that these tissue-level and whole-organism level marine mussel metrics will be impacted by prolonged exposure to these drugs, and that interactive effects will be apparent in mixture concentrations. The hypothesis is that antibiotic treatments will interfere with M. californianus algal feeding rates or digestion, and will result in overall suppression of growth, mass, condition index, and gonado-somatic index in the higher treatment levels. I hypothesize that the effect may be more pronounced in mixture treatments of the drugs, due to the documented synergistic effects of SMX and TRI on organisms in combination (Nord et al. 1974). This study targets data gaps in emerging antibiotic pharmaceutical contaminants research: 1) mixture effects of pharmaceuticals

which are known to act synergistically, 2) the impacts to whole organism physiology and function; 3) the effects of long-term exposure periods (on the scale of months) 4) effects of environmentally-relevant levels.

\section{Methods}

\section{Study Organisms and Acclimation Conditions}

Approximately 750 marine mussels (Mytilus californianus) between 1.5 and 2.8 $\mathrm{cm}$ in length were collected on September 7, 2015 from Rockaway Beach in Tillamook County, Oregon. Mussels were first grouped for 1 week in 23 liters of Instant Ocean seawater in a tank with 32 parts per thousand (ppt) salinity, and water quality was monitored to ensure appropriate ammonia, nitrite, nitrate, and $\mathrm{pH}$ conditions. Mussels were randomly distributed to test jars to acclimatize for 2 weeks, with 9 mussels per 16 
oz. jar, in $400 \mathrm{ml}$ of water. Throughout the experiment, mussels were kept in Instant Ocean seawater pre-treated with ammonia, nitrite, and nitrate reducers to maintain tank environments.

\section{Experimental Design}

Experimental tests were performed over 12 weeks using 16-oz glass jar tanks comprised of Instant Ocean seawater maintained at 32 ppt salinity. Mussels jars were kept in a $15 \pm 1{ }^{\circ} \mathrm{C}$ water bath, using a $12 \mathrm{hr}$ light/dark illumination cycle with 24 hour/day aeration. There were four 32-watt natural full-spectrum bulbs with 2850 lumens each over the water bath. The 81 jars had full water changes every 10 days, and were treated according to an antibiotic treatment plan, consisting of control, low and high concentrations of SMX and TRI antibiotic concentrations determined based on Gaw et al. (2015) averages of worldwide occurrence data, in a 3x3 factorial design (Table 3.1). With the worldwide occurrence data, the high ranges were averaged and the low ranges were averaged of SMX and TRI individually for all reported instances in which both were present to arrive at the test concentrations (Table 3.1) (Gaw et al. 2014). These antibiotic mixture treatments were applied every 10 days (mimicking effluent pulse effects) following the full water changes, with nine replicate jars for each mixture treatment concentration described in Table 3.1 .

Each jar began with 9 mussels per jar, and 3 mussels were sub-sampled from each jar at week 6 in order to measure tissue indices. A background mortality rate of less than $3.6 \%$ was experienced throughout the duration of the 12 -week experiment. All Instant Ocean seawater was pre-treated with ammonia, nitrite, and nitrate reducers to maintain tank environments, and ammonia, nitrite, nitrate, $\mathrm{pH}$, and salinity levels were 
monitored in random jar checks during specified points during the water change cycle. To ameliorate unavoidable evaporation across jars and improve water quality, every 5th day between water changes, $50 \mathrm{ml}$ of slightly under-salinated ( $29 \mathrm{ppt})$ saltwater was added to all jars to bring jar levels up to $400 \mathrm{ml}$ and proper salinity. Every 3 days, mussels were fed non-viable Isochyris galbana algae based on Reed Mariculture's ${ }^{\mathrm{TM}}$ feeding guidelines with feeding volume scaled by the number of mussels per jar at any given time.

Table 3.1. Antibiotic mixture treatment concentrations (high and low values are based off of worldwide occurrence data range averages). The 9 treatment levels (grey) are comprised of control (0), low, and high levels in every combination. For each treatment, $\mathrm{n}=9$. $\mathrm{SMX}=$ sulfamethoxazole, $\mathrm{TRI}=$ trimethoprim, with bold indicating SMX levels.

\begin{tabular}{|c|c|c|c|c|}
\hline \multicolumn{2}{|c|}{} & \multicolumn{3}{c|}{ SMX } \\
\cline { 2 - 5 } & 0 & $\begin{array}{c}7.5 \mathrm{ng} / \mathrm{L} \\
\text { (Low) }\end{array}$ & $75 \mathrm{ng} /$ L (High) \\
\hline \multirow{3}{*}{ TRI } & 0 & $0-0$ & Low - 0 & High - 0 \\
\cline { 2 - 5 } & $8.5 \mathrm{ng} /$ L (Low) & 0 - Low & Low - Low & High - Low \\
\cline { 2 - 5 } & $85 \mathrm{ng} /$ L (High) & 0 - High & Low - High & High - High \\
\hline
\end{tabular}

\section{Antibiotics}

Sulfamethoxazole and trimethoprim were purchased from Sigma-Aldrich (St. Louis, MO, USA). Stock solutions of each antibiotic were prepared by dissolving the selected antibiotic with deionized water, and concentrations of each antibiotic in experimental tests were then adjusted from each stock solution using serial dilutions, allowing for a negligible volume of 30-34 $\mu$ added to each jar every 10 days, to mimic 
effluent pulses. The half-life in water for primary degradation of trimethoprim is

estimated to be $>42$ days, and for sulfonamide drugs is $>21$ days (Kümmerer 2004).

\section{Endpoints}

In response to the antibiotic treatment levels applied, various endpoints were measured in the mussels throughout the 12-week experiment (Table 3.2)

Table 3.2. Endpoints measured in test mussels in response to treatment of antibiotics SMX and TRI mixtures.

\begin{tabular}{|c|c|}
\hline $\begin{array}{c}\text { Endpoints Measured } \\
\text { (in response to treatments) }\end{array}$ & Frequency \\
\hline Growth rates: dimensions (L, W, H), mass & Week $0,6,9,12$ \\
\hline Feeding rates (algal clearance) & Week 2, 4, 6, 8, 10,12 \\
\hline $\begin{array}{c}\text { Condition Index (CI), } \\
\text { Gonado-Somatic Tissue Index (GSI) }\end{array}$ & Week 6,12 \\
\hline
\end{tabular}

\section{Mussel Growth}

To examine differences in growth rates over time, all mussels in the experiment were measured in three dimensions using calipers (Mitutoyo 500 196-30) accurate to $\pm 0.01 \mathrm{~mm}$, and were massed using a balance accurate to \pm 0.001 grams (Southern Laboratories) (Suchanek 1981). Length here is defined as the maximum anterior (umbo) dimension to the posterior dimension, height as maximum dorsal-ventral dimension of the shell measured perpendicular to the hinge, and width as the maximum left-right dimension with both valves appressed (Larson et al. 2014). These measurements were taken at weeks $0,6,9$, and 12 (at the end of the experiment). Percent change in 
dimensions was calculated as $\%$ change $=\left(\right.$ Dimension $_{\mathrm{t}}-$ Dimension $\left._{0}\right) /$ Dimension $\left.\left._{0}\right)\right) *$ 100 for each dimension measurement for time " $\mathrm{t}$ " as compared to initial time " 0 ," and the response variable approximation of mussel shell volume $\left(\mathrm{mm}^{3}\right)$ was taken as Length * Width * Height of each mussel at each sampling event. At week 6 sampling, within-tank means are comprised of 9 mussels per tank, and at weeks 9 and 12, 6 mussels per tank (as mussels were subsampled at week 6).

Feeding Rates

Following the methods of Berg et al. (1996) for measuring mussel feeding rates (algal clearance), three randomly selected jars per treatment level were monitored biweekly, and algal cell densities within the jars were measured with a Beckman Coulter Counter at two time points: 1) just after feeding, and 2) approximately 2-3 hours postfeeding to determine the uptake rate by the filter-feeding mussels. Exact time is accounted for (in $\#$ of minutes) in the equation: Clearance rate $=\left[\left(\operatorname{lnC}_{0}-\operatorname{lnC}_{t}\right)-\left(\operatorname{lnC}^{\prime}{ }_{0}-\right.\right.$ $\left.\left.\operatorname{lnC}_{\mathrm{t}}{ }_{\mathrm{t}}\right)\right] * \mathrm{~V} / \mathrm{t}$, where $\mathrm{C}_{0}=$ algal concentration at the start of the test period, $\mathrm{C}_{\mathrm{t}}=$ algal concentration at the end of the test period, $\mathrm{C}^{\prime}{ }_{0}=$ algal concentration of the control jar at the beginning of the experiment, $\mathrm{C}_{\mathrm{t}}=$ algal concentration of the control jar at the end of the test period, $\mathrm{V}=$ experimental volume, and $\mathrm{t}=$ time (minutes). Clearance rates were divided by the number of mussels per jar at each sampling event to obtain a per mussel average. Control jars with algae added but without mussels were measured to identify algal settling rates on the glassware. Randomly selected jars were also measured to confirm that pre-feeding background rates of particles within the same size class were not significant in these particle counter measurements. 


\section{Body condition: Gonado-somatic Index \& Condition Index}

Methods for measuring gonado-somatic index (GSI) and mussel condition index (CI) are based on Schiedek et al. (2006). At week 6, three mussels from each jar were sub-sampled and frozen to measure CI and GSI (for reproductively mature mussels), and again at week 12 . The measurements were: $\mathrm{CI}=$ tissue dry weight $(\mathrm{g}) /$ shell length $(\mathrm{cm})$. 100], and GSI = gonad weight $(\mathrm{g}) /$ somatic weight $(\mathrm{g}) \cdot 100$ (standardized to shell length at each sampling period). Mussels were dissected and frozen, and then dried for 48 hours at $60^{\circ} \mathrm{C}$ to obtain dry tissue weights (Schiedek et al. 2006).

\section{Data Analysis}

For each analysis, within-tank means for all mussel growth parameters, GSI, CI, and algal clearance rates were calculated. Repeated-measures two-way ANOVAs were calculated using the R studio version 0.98.1062 package “ez" to analyze differences in parameters at different treatment levels and sub-sample time periods (R Development Core Team 2008, Lawrence 2015). Antibiotic treatment levels of both SMX and TRI and sampling date were factors, with tank number included as an error term to account for the non-independence between temporal samples. The assumption of sphericity was tested for each parameter using the Mauchly test and adjusted using Greenhouse-Geisser corrections. Normality and homogeneity of variance were assessed through graphical inspection of the model residuals, and data were either square-root or log-transformed to meet assumptions. Post-hoc multiple pair-wise comparisons between treatment groups and sample dates were performed and a Bonferroni correction was applied. For parameters in which an interactive effect was significant, an interaction plot was 
generated and examined for the parameter's final sampling date. Effects were considered significant at or below $\alpha=0.05$.

\section{Results}

\section{Mussel growth}

Total percent change in mussel volume was significantly affected by contaminant concentration, particularly by SMX level (Table 3.3, Figure 3.1A and B, Figure 3.2A), with faster overall growth in control groups (Figure 3.1A, Figure 3.2A). While there was also an effect of the sample date on percent change in mussel volume, treatment effects were not dependent on sample date, and there was no effect of TRI or interactive drug effect (Table 3.3).

Overall growth in percent change of shell length followed a different pattern over time with mussels exposed to contaminants having the greatest increase in length. Change in shell length was significantly increased by sample date and TRI * SMX * Date, with the interaction of the two drugs increasing percent change in length over time (Figure 3.1C and D, Figure 3.2B, Table 3.3). The extent of this percent change in length after 12 weeks $[0.45(\mathrm{SE} \pm 0.04) \%$, however, was less overall than the percent change in width $[1.39(\mathrm{SE} \pm 0.06) \%]$ for all treatments (Figure 3.1E and F, Figure 3.2C). Percent change in mussel width was significantly suppressed by higher SMX levels, but was not significantly affected by levels of TRI concentrations (Table 3.3, Figure 3.1E and F). Width percent change was significantly less in the highest (S2) treatment mussels as compared to controls by the end of the study $(p=0.005)$. Percent change in mussel height was largely negative over time, but was significantly suppressed by higher SMX levels (Table 3.3, Figure 3.1G and H, Figure 3.2D), with lower overall percent change in height 
in S2 than in control groups (Figure 31.G). Interactively, TRI and SMX significantly increased height in the S1-T2 treatment by week 12, but overall SMX elicited the most significant suppressive effect $\left(F_{72,144}=8.48, p=<0.001\right)$.

Mussel wet biomass percent change was significantly affected by the interactions of SMX * Date (Table 3.3). Week 6 control SMX mussels (S0) had a significantly lower percent change in wet biomass than the highest treatment ( $\mathrm{S} 2, p=0.049)$, but by Week 12 , these same controls had a higher average percent change in mass than the other treatments, though not significantly different (Table 3.3, Figure 3.1I, Figure 3.2E). TRI * SMX interactions resulted in increased mass in S2-T2 treated mussels by week 12 (Table 3.3, Figure 3.1I, Figure 3.2E). Condition indices elucidate this further by standardizing these mass changes by dry tissue weight and shell length (Figure 3.3A and B). 

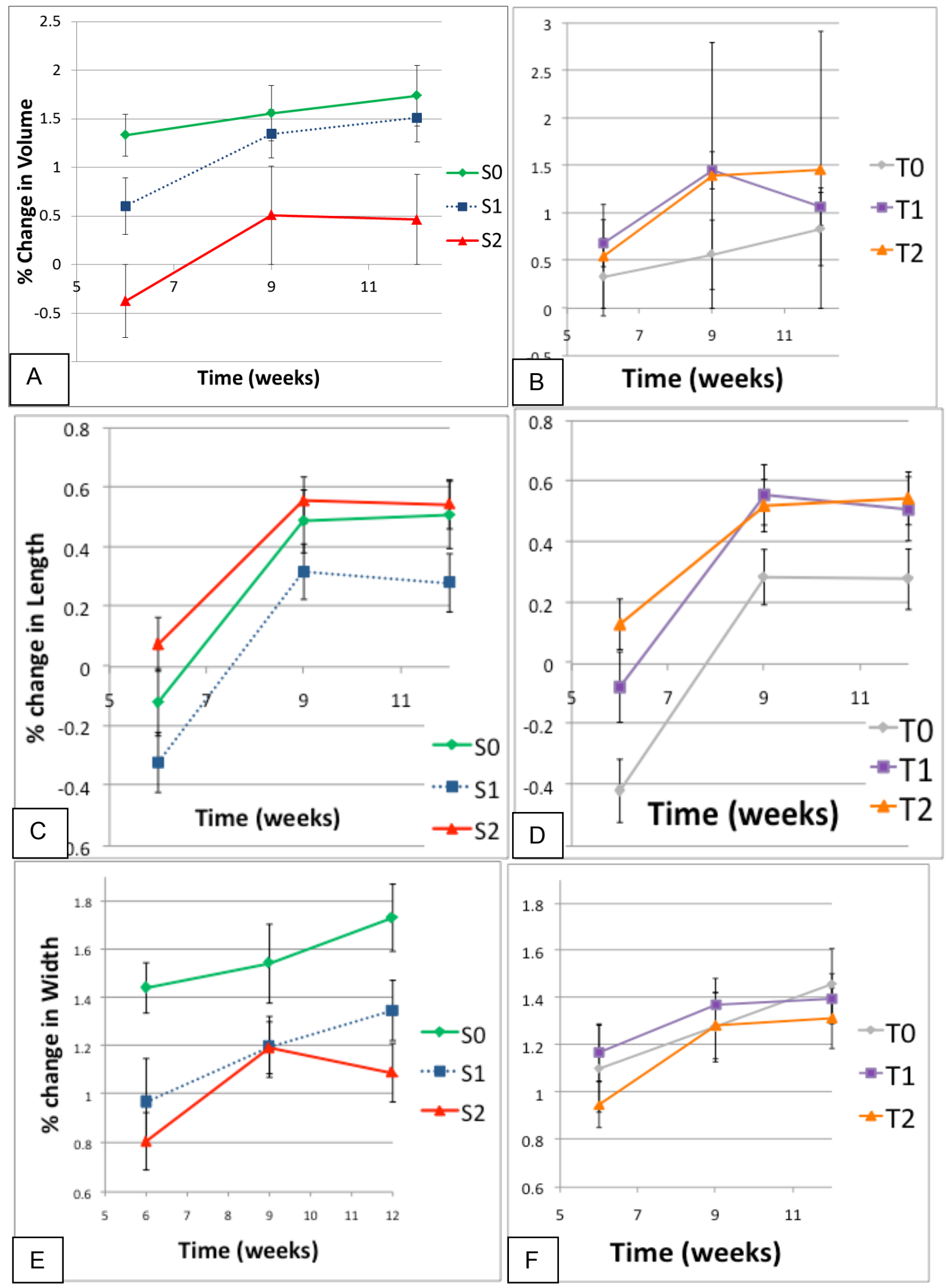


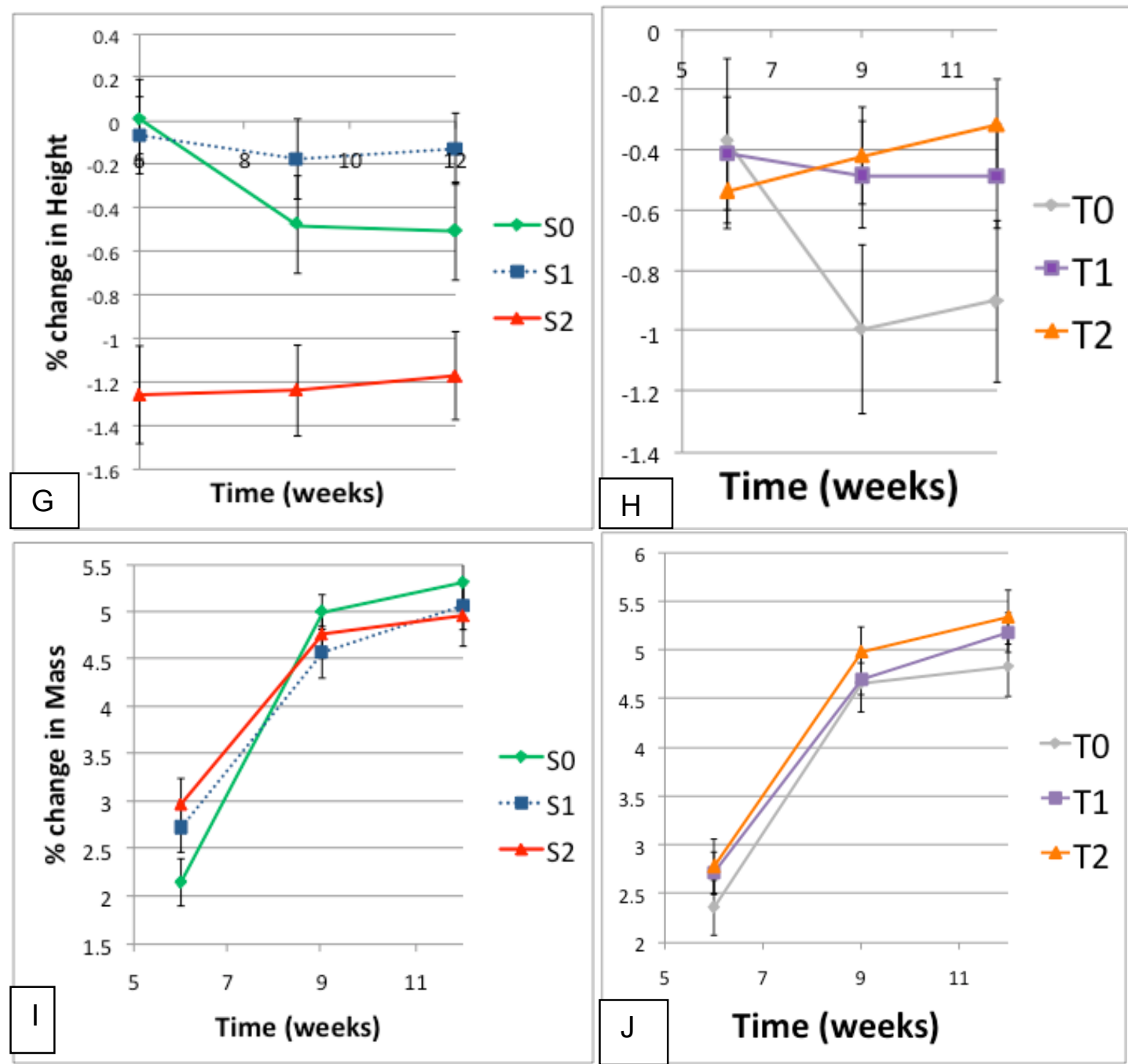

Figure 3.1. The average percent change in mussel growth parameters of total shell volume (A and B), length ( $\mathrm{C}$ and $\mathrm{D})$, width (E and $\mathrm{F})$, height $(\mathrm{G}$ and $\mathrm{H})$, and mass (I and $\mathrm{J})$ across SMX and TRI treatment groups over the experimental period. Error bars reflect $\pm \mathrm{SE}$ of the mean. 


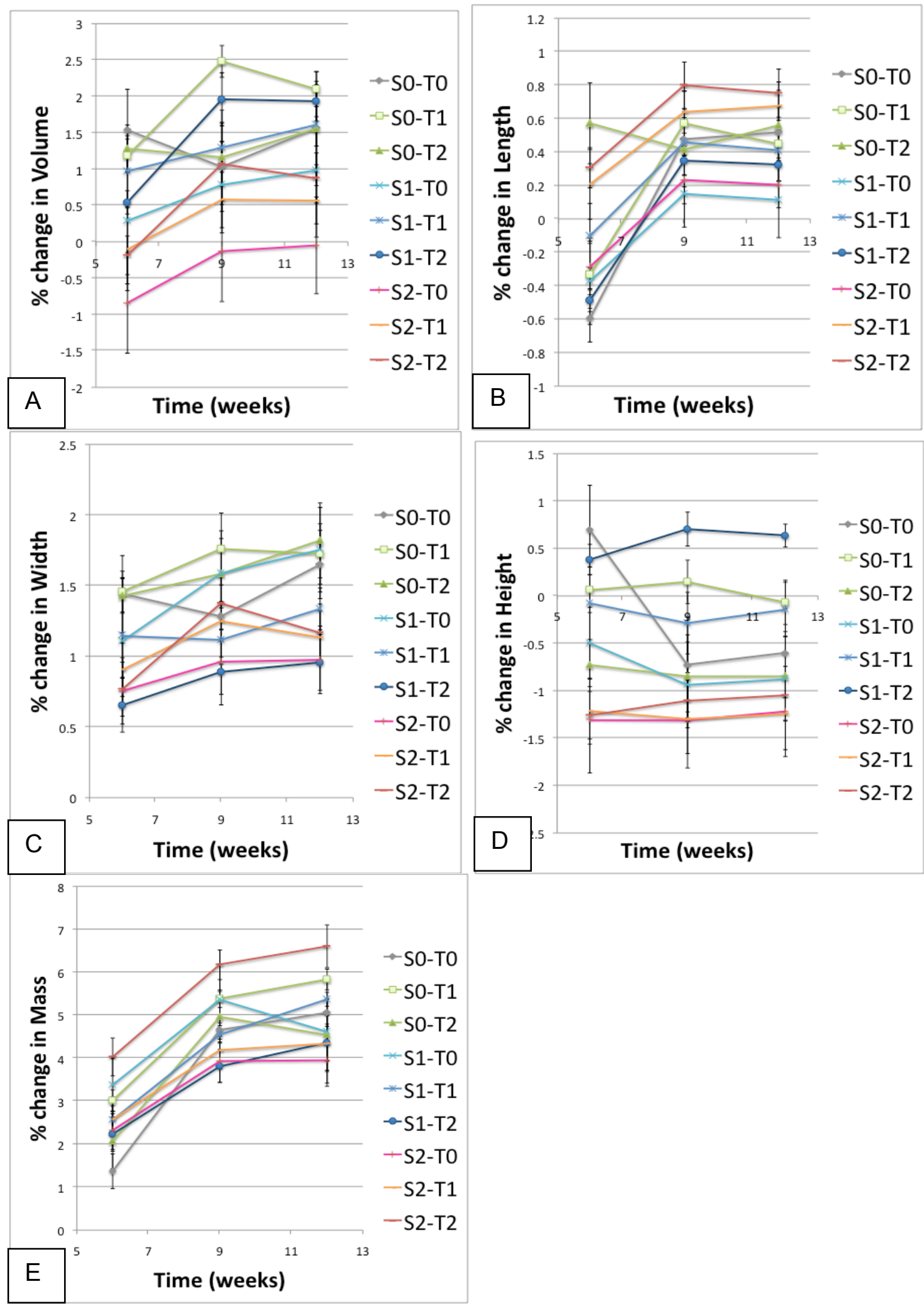

Figure 3.2. The average percent change in mussel growth parameters of total shell volume (A), length (B), width (C), height (D), and mass (E) across all SMX and TRI treatment mixtures over the experimental period. Error bars reflect $\pm \mathrm{SE}$ of the mean. 
Table 3.3. Repeated-measures ANOVA results for growth factors. Response variables were log-transformed (volume) or square-root transformed (L, H, W, Mass). SMX or TRI refers to antibiotic concentration levels; significant factors $(p<0.05)$ are shown in bold.

\begin{tabular}{|c|c|c|c|c|c|c|}
\hline $\begin{array}{c}\text { Growth } \\
\text { parameter } \\
\text { (\% change) }\end{array}$ & Factor & SS & MS & df & $F$ & $p$ \\
\hline \multirow{9}{*}{ Volume } & TRI & 18.60 & 9.30 & 2 & 1.59 & 0.211 \\
\hline & SMX & 77.59 & 38.80 & 2 & 6.62 & 0.002 \\
\hline & Sample Date & 24.52 & 12.26 & 2 & 19.27 & $<0.001$ \\
\hline & TRI*SMX & 8.90 & 2.22 & 4 & 0.38 & 0.822 \\
\hline & TRI * Sample Date & 3.19 & 0.80 & 4 & 1.25 & 0.292 \\
\hline & SMX * Sample Date & 3.79 & 0.95 & 4 & 1.49 & 0.209 \\
\hline & TRI * SMX * Date & 9.25 & 1.16 & 8 & 1.82 & 0.078 \\
\hline & Error among groups & 421.70 & 5.86 & 72 & & \\
\hline & Error within groups & 91.62 & 0.64 & 144 & & \\
\hline \multirow{9}{*}{ Length } & TRI & 5.57 & 2.79 & 2 & 4.03 & 0.021 \\
\hline & SMX & 3.75 & 1.88 & 2 & 2.71 & 0.07 \\
\hline & Sample Date & 17.59 & 8.80 & 2 & 134.84 & $<0.001$ \\
\hline & TRI*SMX & 2.65 & 0.66 & 4 & 0.96 & 0.44 \\
\hline & TRI * Sample Date & 0.87 & 0.22 & 4 & 3.34 & 0.012 \\
\hline & SMX * Sample Date & 0.27 & 0.07 & 4 & 1.03 & 0.39 \\
\hline & TRI * SMX * Date & 4.31 & 0.54 & 8 & 8.25 & $<0.001$ \\
\hline & Error among groups & 49.73 & 0.69 & 72 & & \\
\hline & Error within groups & 9.39 & 0.07 & 144 & & \\
\hline \multirow{9}{*}{ Height } & TRI & 4.73 & 2.36 & 2 & 0.72 & 0.490 \\
\hline & SMX & 55.61 & 27.81 & 2 & 8.48 & $<0.001$ \\
\hline & Sample Date & 1.74 & 0.87 & 2 & 5.16 & $\mathbf{0 . 0 0 7}$ \\
\hline & TRI*SMX & 30.46 & 7.62 & 4 & 2.32 & 0.065 \\
\hline & TRI * Sample Date & 4.73 & 1.18 & 4 & 7.04 & $<0.001$ \\
\hline & SMX * Sample Date & 3.07 & 0.77 & 4 & 4.57 & 0.002 \\
\hline & TRI * SMX * Date & 3.95 & 0.49 & 8 & 2.94 & 0.005 \\
\hline & Error among groups & 236.16 & 3.28 & 72 & & \\
\hline & Error within groups & 24.22 & 0.17 & 144 & & \\
\hline \multirow{9}{*}{ Width } & TRI & 0.75 & 0.38 & 2 & 0.32 & 0.724 \\
\hline & SMX & 12.71 & 6.35 & 2 & 5.48 & 0.006 \\
\hline & Sample Date & 4.41 & 2.21 & 2 & 12.53 & $<0.001$ \\
\hline & TRI*SMX & 6.26 & 1.57 & 4 & 1.35 & 0.260 \\
\hline & TRI * Sample Date & 0.38 & 0.10 & 4 & 0.54 & 0.706 \\
\hline & SMX * Sample Date & 0.87 & 0.22 & 4 & 1.24 & 0.296 \\
\hline & TRI * SMX * Date & 1.41 & 0.18 & 8 & 1.00 & 0.435 \\
\hline & Error among groups & 83.54 & 1.16 & 72 & & \\
\hline & Error within groups & 25.34 & 0.18 & 144 & & \\
\hline \multirow{9}{*}{ Mass } & TRI & 6.32 & 3.16 & 2 & 0.55 & 0.581 \\
\hline & SMX & 2.40 & 1.20 & 2 & 0.21 & 0.813 \\
\hline & Sample Date & 281.06 & 140.53 & 2 & 138.68 & $<0.001$ \\
\hline & TRI*SMX & 107.59 & 26.90 & 4 & 4.65 & 0.002 \\
\hline & TRI * Sample Date & 3.15 & 0.79 & 4 & 0.78 & 0.543 \\
\hline & SMX * Sample Date & 12.61 & 3.15 & 4 & 3.11 & 0.017 \\
\hline & TRI * SMX * Date & 11.56 & 1.44 & 8 & 1.43 & 0.191 \\
\hline & Error among groups & 416.47 & 5.78 & 72 & & \\
\hline & Error within groups & 145.92 & 1.01 & 144 & & \\
\hline
\end{tabular}




\section{Feeding Rates}

At most sample periods, feeding rates were not significantly affected by experimental parameters, except for sample date (Table 3.4). Algal clearance rates by control mussels were significantly higher than treatment mussels of aggregated SMX levels only on experimental Day 30 [S0: 0.25 (SE 0.03) cells $\mathrm{mL}^{-1} \mathrm{~min}^{-1}$ versus S1: 0.17 (SE 0.03) cells $\mathrm{mL}^{-1} \min ^{-1}$ and S2: $0.16(\mathrm{SE} 0.02)$ cells $\left.\mathrm{mL}^{-1} \mathrm{~min}^{-1}, \mathrm{~F}_{2,24}=5.14, \mathrm{P}=0.013\right]$.

\section{Body condition: Gonado-somatic Index \& Condition Index}

The mean tank condition index (CI) was affected by both SMX and TRI treatment levels over time. Mean CI significantly decreased from week 6 to week 12 in the highest treatment concentrations of SMX and TRI, while it increased for control groups and lower treatment concentrations (Figure 3.3A and E). The following factors significantly influenced CI: TRI levels, SMX levels, interactions of TRI * Sample Date, SMX * Sample Date, and TRI * SMX * Date (Table 3.4, Figure 3.4A and E). The interaction of SMX and TRI treatments suppressed CI in mixture treatment levels as compared to the treatment concentrations without TRI.

The gonado-somatic index (GSI) of mussels (standardized to mussel length) was significantly influenced by TRI and the interaction of TRI * SMX (Figure 3.3C and D, Table 3.4). Interactively, the highest levels of TRI and SMX resulted in higher GSI at week 12 . The week 6 GSI:length index was significantly higher in control treatment and treatments with SMX only than those treated with any concentration of TRI (Figure 
3.3B). Week 12 GSI:length exhibited higher mean GSI:length values for control S0 mussels than S2 treated mussels, though not significantly (Figure 3.3C).

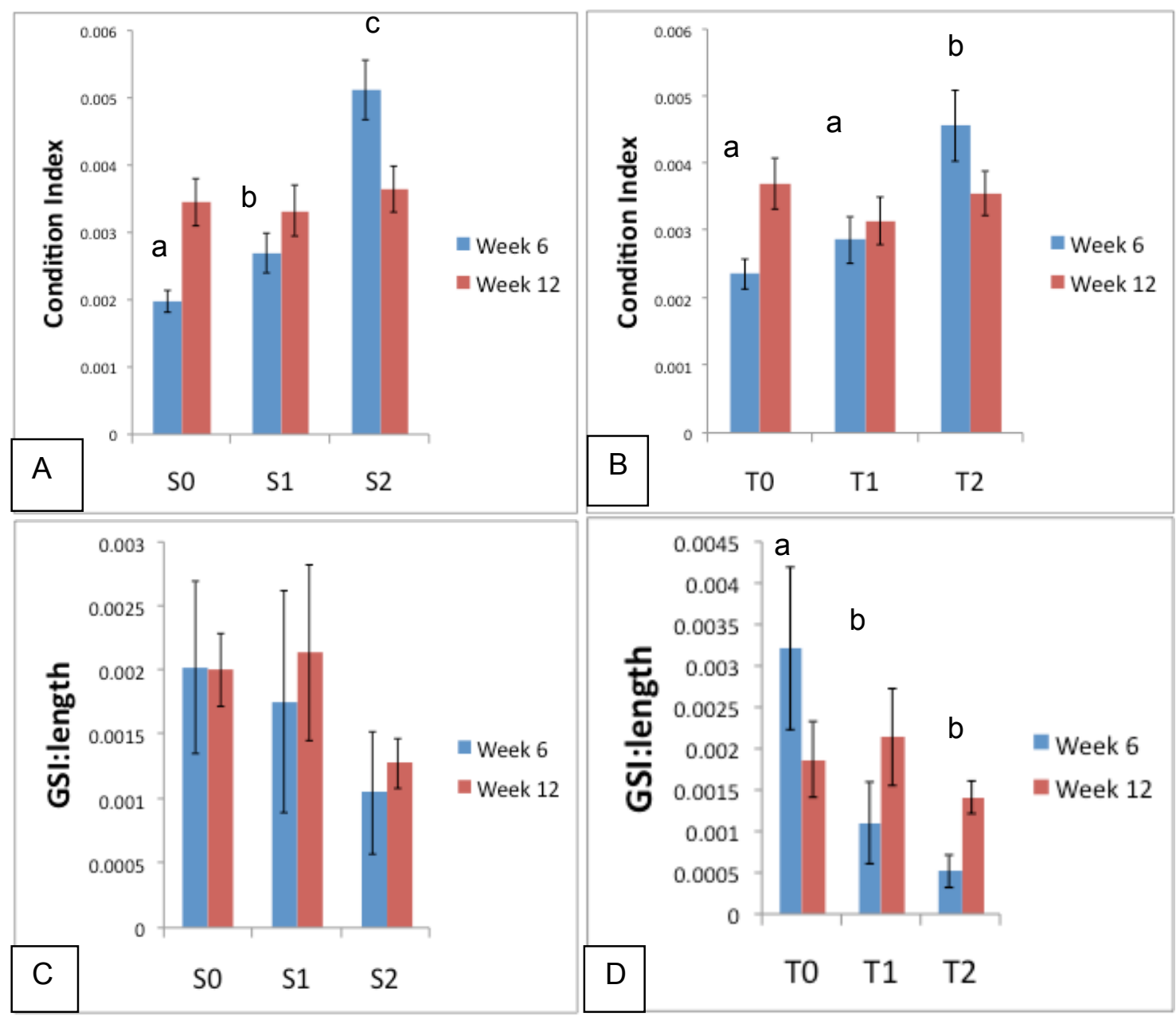




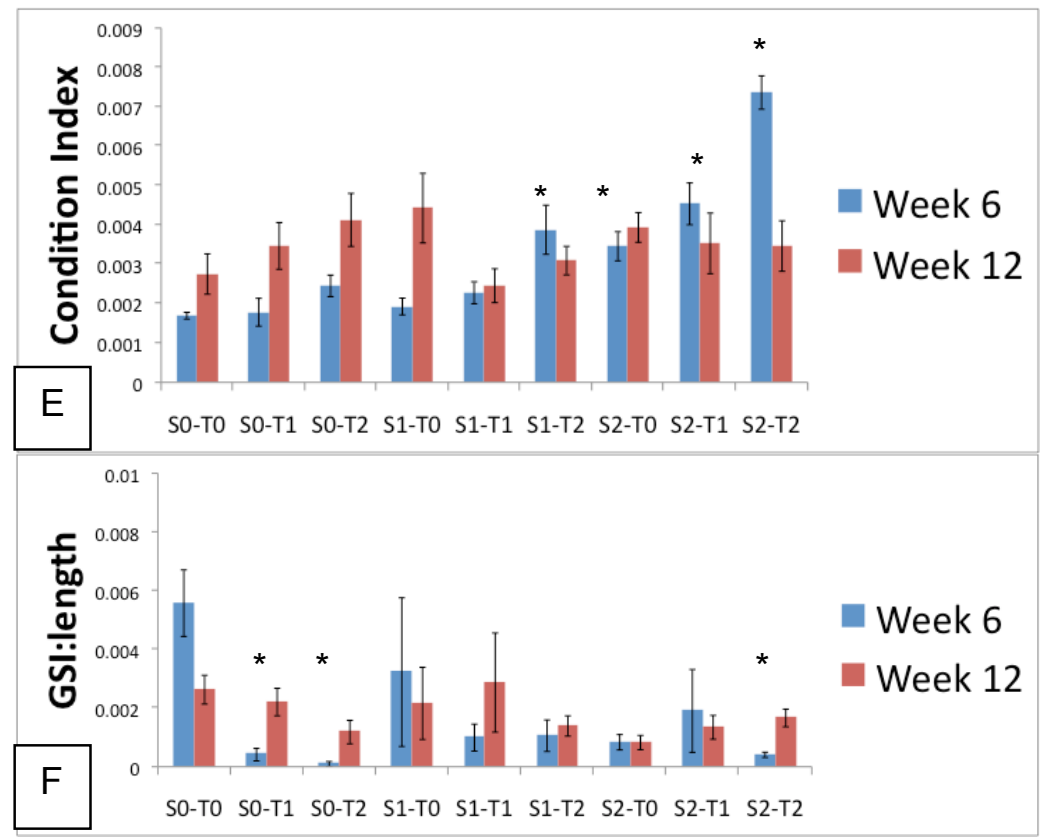

Figure 3.3. Mean mussel tissue indices at weeks 6 and 12 in response to antibiotic treatments for A) CI by SMX level, B) CI by TRI level, C) GSI by SMX level, D) GSI by TRI level, D) CI by SMX and TRI mixtures and E) GSI by SMX and TRI mixtures.

Lowercase letters and asterisks $(*=$ different than control) represent significant differences, $p<0.05$. 
Table 3.4. Repeated measures ANOVA results for mean tank body condition indices (CI and GSI) and algal clearance rates, including $2^{\text {nd }}$, and $3^{\text {rd }}$ order interactions. Response variables were log-transformed. SMX or TRI refers to antibiotic concentrations;

Significant factors and $p$-values $<0.05$ are shown in bold.

\begin{tabular}{|c|c|c|c|c|c|c|}
\hline $\begin{array}{c}\text { Dependent } \\
\text { variable }\end{array}$ & Factor & SS & MS & df & $F$ & $p$ \\
\hline \multirow{9}{*}{$\begin{array}{l}\text { Condition } \\
\text { Index } \\
\text { (CI) }\end{array}$} & TRI & 3.04E-05 & $1.52 \mathrm{E}-05$ & 2 & 8.90 & $<0.001$ \\
\hline & SMX & $6.65 \mathrm{E}-05$ & $3.33 \mathrm{E}-05$ & 2 & 19.46 & $<0.001$ \\
\hline & Sample Date & $1.38 \mathrm{E}-06$ & $1.38 \mathrm{E}-06$ & 1 & 0.73 & 0.396 \\
\hline & TRI*SMX & $1.02 \mathrm{E}-05$ & $2.55 \mathrm{E}-06$ & 4 & 1.49 & 0.218 \\
\hline & TRI * Sample Date & $2.90 \mathrm{E}-05$ & $1.45 \mathrm{E}-05$ & 2 & 7.69 & 0.001 \\
\hline & SMX * Sample Date & $4.84 \mathrm{E}-05$ & $2.42 \mathrm{E}-05$ & 2 & 12.82 & $<0.001$ \\
\hline & TRI * SMX * Date & $2.65 \mathrm{E}-05$ & $6.63 \mathrm{E}-06$ & 4 & 3.51 & 0.013 \\
\hline & Error among groups & $9.23 \mathrm{E}-05$ & $1.71 \mathrm{E}-06$ & 54 & & \\
\hline & Error within groups & $1.02 \mathrm{E}-04$ & $1.89 \mathrm{E}-06$ & 54 & & \\
\hline \multirow{9}{*}{$\begin{array}{c}\text { Gondo-somatic } \\
\text { index } \\
\text { (GSI) }\end{array}$} & TRI & $3.68 \mathrm{E}-04$ & $1.84 \mathrm{E}-04$ & 2 & 5.02 & 0.010 \\
\hline & SMX & $5.27 \mathrm{E}-05$ & $2.63 \mathrm{E}-05$ & 2 & 1.80 & 0.175 \\
\hline & Sample Date & $1.89 \mathrm{E}-05$ & $1.89 \mathrm{E}-05$ & 1 & 0.17 & 0.679 \\
\hline & TRI*SMX & $6.17 \mathrm{E}-05$ & $1.54 \mathrm{E}-05$ & 4 & 2.94 & 0.028 \\
\hline & TRI * Sample Date & $3.73 \mathrm{E}-05$ & $1.87 \mathrm{E}-05$ & 2 & 2.67 & 0.079 \\
\hline & SMX * Sample Date & $8.61 \mathrm{E}-07$ & $4.31 \mathrm{E}-07$ & 2 & 0.06 & 0.940 \\
\hline & TRI $*$ SMX $*$ Date & $2.97 \mathrm{E}-05$ & $7.43 \mathrm{E}-06$ & 4 & 1.06 & 0.384 \\
\hline & Error among groups & $2.83 \mathrm{E}-04$ & $5.24 \mathrm{E}-06$ & 54 & & \\
\hline & Error within groups & $3.78 \mathrm{E}-04$ & $7.00 \mathrm{E}-06$ & 54 & & \\
\hline \multirow{9}{*}{ Clearance rate } & TRI & 0.05 & 0.02 & 2 & 0.24 & 0.793 \\
\hline & SMX & 0.03 & 0.02 & 2 & 0.18 & 0.837 \\
\hline & Sample Date & 1.13 & 0.23 & 5 & 9.35 & $<0.001$ \\
\hline & TRI*SMX & 0.24 & 0.06 & 4 & 0.62 & 0.656 \\
\hline & TRI * Sample Date & 0.12 & 0.01 & 10 & 0.50 & 0.887 \\
\hline & SMX * Sample Date & 0.21 & 0.02 & 10 & 0.88 & 0.557 \\
\hline & TRI $*$ SMX * Date & 0.35 & 0.02 & 20 & 0.73 & 0.784 \\
\hline & Error among groups & 11.97 & 0.67 & 18 & & \\
\hline & Error within groups & 1.73 & 0.02 & 90 & & \\
\hline
\end{tabular}

\section{Discussion}

Long-term (3 month) exposure to antibiotic mixtures at environmentally-relevant concentrations affected mussel growth rates and body condition. Although results indicate that mussel algal clearance rates were not affected by low concentrations of antibiotics, the growth metrics indicate a reduced ability of the mussels to assimilate their algal feed. Specifically, whole-body metrics of fitness such as total shell volume and 
biomass growth rates, as well as body condition indices, were significantly affected over the course of several months. Total percent change in shell volume, an aggregate measure of each mussel's length, width, and height, was significantly suppressed by the highest SMX treatments. Previous research has found that mussels tend to become narrower (longer and less wide) under conditions of high density and at low food availability, but food and density levels were consistent across treatments in this experiment (AlunnoBruscia et al. 2001). Thus, the suppression in shell volume growth rate observed, and the strongly suppressed width over time (which significantly diverged from controls in the highest aggregated SMX treatment but was unaffected by TRI parameters), indicates that antibiotic treatments may have imposed disruptions in food assimilation, possibility due to disturbance of the mussel gut digestion microbiome (mimicking lack of food).

Possible disruptions in the gut digestion microbiome are corroborated by the fact that mean condition index decreased in the high SMX treatment levels in the latter half of the study. Though SMX levels are the primary driver of effects in this mixture study, there were interactive effects between SMX and TRI for a number of parameters - both body condition and growth dimensions. Condition index was sensitive to both SMX and TRI, with suppressive interactive effects found with both drugs and across sample dates. GSI on the other hand, was affected by TRI levels and positively influenced by the interaction of TRI * SMX. Moreover, though change in shell volume was driven by SMX level, the individual morphological components (length, width, and height) exhibited differential sensitivities to these mixture concentrations. This indicates that mixture studies that include measurements across diverse growth dimensions are vitally important, as such studies more closely mimic real-world exposures and the array of 
potential effects exhibited due to the variability caused by drugs of the same class with different target sites.

SMX may have had a greater influence on mussel growth than TRI due to the potential increased toxicity of the photo-degradation products of SMX in seawater (Trovó et al. 2009b). Both SMX and TRI are not readily biodegradable in seawater, but they transform through photo-degradation with a half-life of approximately 42 days for trimethoprim and 21 days for sulfonamide drugs (Benotti and Brownawell 2007, 2009, Kümmerer 2008, Larcher and Yargeau 2012). Previous research shows that photodegradation products may have a greater toxicity than the parent molecule. Two studies by Trovó et al. (2009a and 2009b) found that the toxicity of SMX increased over the course of the test periods, with the authors concluding that the toxicity of the SMX phototransformation products generated were higher than that of the original compound. Trimethoprim photo-degradation studies in saltwater indicate "only a small increase" in the toxicity on test organisms, with intermediates which were moderately toxic for the organisms tested (Sirtori et al. 2010, Fatta-Kassinos et al. 2011). Thus SMX is degrading more quickly (with its shorter half-life), and potentially with more toxic degradation products. Assessments of sub-lethal effects of transformation products must be included in the suite of pharmaceutical contaminant research to more closely simulate environmental conditions.

As efficient filter feeders, mussels in both laboratory and field studies have demonstrated bioaccumulation of pharmaceuticals (Benotti and Brownawell 2007, McEneff et al. 2014). Antibiotics such as SMX and TRI find their way into the 
environment mainly through effluent of wastewater treatment plants, and are considered "pseudo-persistent" due to their continued release into the environment (González-Pleiter et al. 2013). In laboratory settings, mussel sub-cellular endpoints such as genotoxic and immunotoxic metrics have responded to a suite of pharmaceuticals, including antibiotics (Gagné et al. 2006, Lacaze et al. 2015). Our findings support the indication of suppressed health characteristics of mussels facing exposure to antibiotics. This study offers an understanding of how a benthic foundational intertidal species responds to the presence of SMX and TRI in the water (and likely bioaccumulation in the tissue) over the longterm using whole-organism growth rates and body condition indices, and offers insight on environmental effects of pharmaceutical contaminants, and specifically the suite of antibiotics, that are released into marine ecosystems.

M. californianus, is recognized as a foundation species on the Pacific coast because it creates extensive beds that provide habitat, food and refuge for a wide range of coastal organisms that live on exposed rocky shores (Suchanek 1992, Gaylord et al. 2011). As foundational species in rocky intertidal and subtidal ecosystems, changes in mussel growth, condition, and reproduction could have profound effects on marine coastal communities. This mussel plays an important role as a dominant competitor over much of its range, as it excludes other competitors from accessing primary substrate (Paine 1966, Gaylord et al. 2011). As such, Gaylord et al. 2011 note that "biological diversity of many intertidal communities is linked tightly to the ecological performance of this bivalve.” Therefore, if these important filter feeders are being exposed to pharmaceuticals (from wastewater effluent or through other pathways), and the drugs are 
affecting their growth and condition parameters, shifts in overall population abundance may occur, which could have wide-ranging community-level effects.

Global human population is rapidly growing, people are increasingly using pharmaceutical drugs, and coastal areas are home to $41 \%$ percent of the world population (Gaw et al. 2014, Gu et al. 2010). Along with over-exploitation, habitat loss, and invasive species, contaminants are one of the many identified anthropogenic stressors to the coastal marine environment (Fabbri and Franzellitti 2015). Thus, important coastal marine foundation species such as $M$. californianus mussels may become increasingly vulnerable to pharmaceutical contaminants as these trends continue. Yet, there is still much to be explored in long-term studies examining effects of the cocktail of pharmaceuticals released into ocean waters to understand interactive and cumulative organismal and potential ecosystem-level effects (Boxall 2004). This research contributes to the understanding of the effects on marine mussel growth and condition in response to long-term drug exposure to inform these potential ecosystem-level effects. The ever-growing level of prescription drug consumption and the diverse array of drug classes present in these habitats necessitates mixture studies to inform source management and forestall a long-term largely irreversible contamination load in our marine ecosystems. 


\section{Chapter 4: Conclusions}

Assessing how species across interacting trophic levels of an intertidal system respond to the presence of sulfamethoxazole and trimethoprim in the water offers important information on the environmental effects of anthropogenic pharmaceutical contaminants, and specifically the suite of antibiotics, that are released into marine ecosystems. Photosynthetic primary producer populations (marine microalgae) are suppressed in the presence of environmentally-relevant concentrations of these drugs, thus there is potential for cascading effects in food webs. Additionally, body condition index, growth rate, and reproductive indicators are significantly affected by these substances in benthic foundation species (e.g., marine mussels). The implications of this research contribute directly to the data gaps surrounding pharmaceutical contaminants in that it addresses long-term effects of these emerging contaminants at low-level, mixture exposures by marine organisms. ${ }^{1}$

At this stage, there is a need for further study on the effects of many classes of pharmaceuticals on a wide array of marine organisms (Gaw et al. 2014), but next steps could include systematic approaches to assess higher ecosystem-level effects. Short-term acute ecotoxicology studies likely will not reveal the non-monotonic effects that are observed over the long-term at low concentrations of drugs. I recommend a study approach involving first the identification of the most prevalent pharmaceutical drugs in different classes found within coastal and estuarine environments utilizing occurrence data, and then in a laboratory setting, systematic assessments of the long-term effects of these most prevalent drugs on growth and reproduction of a suite of potentially sensitive

\footnotetext{
${ }^{1}$ To access any original raw data from this study, please email JaclynRTeixeira@gmail.com
} 
target organisms, individually and in combination. Previous research shows that unicellular and structurally simplistic organisms are especially sensitive to pharmaceutical contaminants, so I would recommend that, in the marine environment, there should be a focus on planktonic primary producers, or larval life stages of invertebrates, as non-target organisms potentially sensitive to these drugs (Isidori et al. 2005, El-Bassat et al. 2012). Additionally, the potential for increased toxicity of photodegradation products of prevalent pharmaceuticals should be investigated rigorously in a chemistry and ecotoxicological setting, which will inform ecological studies of the effects of these on marine organisms resulting from long-term exposures.

The potential for antimicrobial-resistant microorganisms (and resultant effects on organism health) due to environmental exposure to antibiotic contaminants is another critical concern (Boxall et al. 2012). The World Health Organization (WHO) has identified the emergence of antimicrobial resistance as one of the serious concerns for health policies in the future (WHO (World Health Organization) 1998). Byrne-Bailey et al. (2009) found the establishment of resistant genes in bacterial isolates from sulfonamide antibiotic-contaminated manured agricultural soils and pig slurry, while Gaze et al. (2011) measured differences in bacterial gene prevalence in sewage-exposed sludge and concluded that "current waste disposal practices may present a significant risk to human health by recycling antibiotic resistant genes of human and animal origin to the wider environment” (Byrne-Bailey et al. 2009, Gaze et al. 2011). In Mytilus edulis mussels, antibacterial agents used in aquaculture caused a proliferation of resistant bacteria in mussels at higher levels in samples taken at the farm after medication than before or in control areas (Ervik et al. 1994). However, it is noted that many questions 
remain in identifying the role pharmaceutical antibiotic contaminants play in antibiotic resistance, as information is limited to a narrow window of antibiotic classes in certain environments (Boxall et al. 2012). Antibiotics in the environment may result in resistant strains of bacteria, and if humans are exposed to these resistant bacteria, there may be impacts to human health.

This study takes a step towards informing management and policy of the potentially harmful, anthropogenically-sourced pharmaceuticals, and their handling techniques. Preventing further contamination is an important step in managing emerging pharmaceutical contaminant effects. This can be achieved, in part, by informing the public that disposing of unwanted drugs in the toilet or in landfills is harmful to the environment, and that pharmaceuticals should instead be taken to approved drop-off points (i.e., police stations in Oregon) for proper handling. At the time of writing, the Food and Drug Administration's (FDA's) website recommends on their page titled "How to Dispose of Unused Medicines" to first try to locate proper drop-off locations, but if that is not possible, to throw the drugs away in plastic bags in the trash, or, if the drugs are especially powerful or dangerous, to get rid of them immediately through flushing down the toilet (U.S. Food and Drug Administration 2016, U.S. Food and Drug Administration (FDA) 2016). FDA environmental assessment expert, Dr. Raanan Bloom is quoted: "While FDA and the Environmental Protection Agency take the concerns of flushing certain medicines in the environment seriously, there has been no indication of environmental effects due to flushing" (U.S. Food and Drug Administration 2016). Concurrently, the Oregon Department of Environmental Quality's (Oregon DEQ) website states a very different message: "Unused drugs kept in medicine cabinets, tossed in the 
garbage, or flushed down the toilet or drain can be serious threats to human and environmental health"(Oregon Department of Environmental Quality 2016). I recommend that these mixed messages to the public should be resolved: the FDA should review the latest science and update their recommendations, and an easily accessible database should be created linking to lists of designated collection sites for each state and Drug Take-Back events (periodically sponsored by the US Drug Enforcement Agency). Stakeholders including wastewater management boards and prescription drug disposal sources such as hospitals should be involved in order to spark conversation in identifying improved handling techniques of the drugs.

Coastal areas contain over $41 \%$ percent of the world population (approximately 2.3 billion people), and more than $50 \%$ of coastal countries have $80-100 \%$ of their total population within $100 \mathrm{~km}$ of the coastline (Gaw et al. 2014). In addition, the use of prescription drugs among people is rapidly increasing (Gu et al. 2010). Thus, coastal marine and estuarine ecosystems may become especially vulnerable areas to pharmaceutical contaminants as these trends continue. The ever-growing level of prescription drug consumption necessitates studies to examine the environmental effects of various classes of drugs present in these habitats to form the scientific basis on which the reevaluation of source management may occur, in order to forestall a long-term largely irreversible contaminant load in our marine ecosystems. 


\section{Literature Cited}

Alunno-Bruscia, M., E. Bourget, and M. Fréchette. 2001. Shell allometry and lengthmass-density relationship for Mytilus edulis in an experimental food-regulated situation. Marine Ecology Progress Series 219:177-188.

Bates, D., M. Maechler, B. Bolker, S. Walker, R. H. B. Christensen, H. Singmann, B. Dai, and G. Grothendieck. 2016. Linear Mixed-Effects Models using "Eigen" and S4, package "lme4." http://lme4.r-forge.r-project.org/lMMwR/lrgprt.pdf. Retrieved March 15, 2016.

Benotti, M. J., and B. J. Brownawell. 2007. Distributions of pharmaceuticals in an urban estuary during both dry- and wet-weather conditions. Environmental Science and Technology 41:5795-5802.

Benotti, M. J., and B. J. Brownawell. 2009. Microbial degradation of pharmaceuticals in estuarine and coastal seawater. Environmental Pollution 157:994-1002.

Berg, D. J., S. W. Fisher, and P. F. Landrum. 1996. Clearance and Processing of Algal Particles by Zebra Mussels (Dreissena polymorpha). Journal of Great Lakes Restoration 22:779-788.

Boothe, D. 2015. Sulfonamides and Sulfonamide Combinations. Antibacterial Agents: Merck Veterinary Manual.

Boxall, A. B. A. 2004. The environmental side effects of medication. EMBO reports 5:1110-1116.

Boxall, A. B. A., M. A. Rudd, B. W. Brooks, D. J. Caldwell, K. Choi, S. Hickmann, E. 
Innes, K. Ostapyk, J. P. Staveley, G. T. Ankley, K. F. Beazley, S. E. Belanger, J. P. Berninger, P. Carriquiriborde, A. Coors, P. C. Deleo, S. D. Dyer, J. F. Ericson, J. P. Giesy, T. Gouin, L. Hallstrom, M. V Karlsson, D. G. Joakim, J. M. Lazorchak, S. Environmental, H. Perspectives, N. September, A. B. A. Boxali, M. A. Rudd, B. W. Brooks, D. J. Caldwell, K. Choi, S. Hickmann, E. In, K. Ostapyk, J. P. Staveley, T. Verslycke, G. T. Ankley, K. F. Beazley, S. E. Belanger, J. P. Berninger, P. Carriquiriborde, A. Coors, P. C. Deleo, S. D. Dyer, J. P. Ericson, F. Gagné, J. P. Giesy, T. Gouin, L. Hallstrom, M. V Karlsson, D. G. J. Larsson, J. M. Lazorchak, F. Mastrocco, A. Mclaughlin, M. E. Mcmaster, R. D. Meyerhoff, R. Moore, J. L. Parrott, J. R. Snape, R. Murray-smith, M. R. Servos, P. K. Sibley, J. Oliver, S. Nora, E. Topp, G. R. Tetreault, V. L. Trudeau, and G. Van Der Kraak. 2012. Pharmaceuticals and personal care products in the environment: what are the big questions? Environmental Health Perspectives, 120:1221-1229.

Byrne-Bailey, K. G., W. H. Gaze, P. Kay, A. B. A. Boxall, P. M. Hawkey, and E. M. H. Wellington. 2009. Prevalence of sulfonamide resistance genes in bacterial isolates from manured agricultural soils and pig slurry in the United Kingdom. Antimicrobial Agents and Chemotherapy 53:696-702.

Christen, V., S. Hickmann, B. Rechenberg, and K. Fent. 2010. Highly active human pharmaceuticals in aquatic systems: A concept for their identification based on their mode of action. Aquatic Toxicology (Amsterdam, Netherlands) 96:167-81. Christensen, A. M., F. Ingerslev, and A. Baun. 2006. Ecotoxicity of Mixtures of Antibiotics Used in Aquacultures. Environmental Toxicology and Chemistry 25:2208-2215. 
Cleuvers, M. 2003. Aquatic ecotoxicity of pharmaceuticals including the assessment of combination effects. Toxicology Letters 142:185-194.

Colborn, T., and C. Clement. 1992. Chemically-induced alterations in sexual and functional development: the wildlife/human connection.e. Princeton Scientific Pub. Co..

Croft, M. T., A. D. Lawrence, E. Raux-Deery, M. J. Warren, and A. G. Smith. 2005. Algae acquire vitamin B12 through a symbiotic relationship with bacteria. Nature 438:90-3.

Daughton, C. G., and T. A. Ternes. 1999. Pharmaceuticals and personal care products in the environment: agents of subtle change? Environmental Health Perspectives 107:907-938.

Duggar, B. M. 2011. Aureomycin: A product of the continuing search for new antibiotics. Annals of the New York Academy of Sciences 1241:163-169.

Eckburg, P. B., E. M. Bik, C. N. Bernstein, E. Purdom, L. Dethlefsen, M. Sargent, S. R. Gill, K. E. Nelson, and D. A. Relman. 2005. Diversity of the human intestinal microbial flora. Science 308:1635-1638.

Eguchi, K., H. Nagase, M. Ozawa, Y. S. Endoh, K. Goto, K. Hirata, K. Miyamoto, and H. Yoshimura. 2004. Evaluation of antimicrobial agents for veterinary use in the ecotoxicity test using microalgae. Chemosphere 57:1733-8.

El-Bassat, R., H. Touliabah, and G. Harisa. 2012. Toxicity of four pharmaceuticals from different classes to isolated plankton species. African Journal of Aquatic Science $37: 71-80$.

Ervik, A., B. Thorsen, V. Eriksen, B. T. Lunestad, and O. B. Samuelsen. 1994. Impact of 
administering antibacterial agents on wild fish and blue mussels Mytilus edulis in the vicinity of fish farms. Diseases of Aquatic Organisms 18:45-51.

Fabbri, E., and S. Franzellitti. 2015. Human pharmaceuticals in the marine environment: Focus on exposure and biological effects in animal species. Environmental Toxicology and Chemistry / SETAC.

Fatta-Kassinos, D., M. I. Vasquez, and K. K??mmerer. 2011. Transformation products of pharmaceuticals in surface waters and wastewater formed during photolysis and advanced oxidation processes - Degradation, elucidation of byproducts and assessment of their biological potency. Chemosphere 85:693-709.

Franzellitti, S., S. Buratti, P. Valbonesi, and E. Fabbri. 2013. The mode of action (MOA) approach reveals interactive effects of environmental pharmaceuticals on Mytilus galloprovincialis. Aquatic Toxicology (Amsterdam, Netherlands) 140-141C:249256.

Gagné, F., C. Blaise, M. Fournier, and P. D. Hansen. 2006. Effects of selected pharmaceutical products on phagocytic activity in Elliptio complanata mussels. Comparative Biochemistry and Physiology - C Toxicology and Pharmacology 143:179-186.

Gaw, S., K. V Thomas, and T. H. Hutchinson. 2014. Sources, impacts and trends of pharmaceuticals in the marine and coastal environment. Philosophical Transactions of the Royal Society of London. Series B, Biological Sciences 369.

Gaylord, B., T. M. Hill, E. Sanford, E. a Lenz, L. a Jacobs, K. N. Sato, A. D. Russell, and A. Hettinger. 2011. Functional impacts of ocean acidification in an ecologically critical foundation species. The Journal of Experimental Biology 214:2586-2594. 
Gaze, W. H., L. Zhang, N. A. Abdouslam, P. M. Hawkey, L. Calvo-Bado, J. Royle, H. Brown, S. Davis, P. Kay, A. B. A. Boxall, and E. M. H. Wellington. 2011. Impacts of anthropogenic activity on the ecology of class 1 integrons and integron-associated genes in the environment. The ISME journal 5:1253-61.

Glassmeyer, S. T., D. W. Koplin, E. T. Furlong, and M. Focazio. 2008. Environmental presence and persistence of pharmaceuticals: an overview. CRC Press.

González-Pleiter, M., S. Gonzalo, I. Rodea-Palomares, F. Leganés, R. Rosal, K. Boltes, E. Marco, and F. Fernández-Piñas. 2013. Toxicity of five antibiotics and their mixtures towards photosynthetic aquatic organisms: implications for environmental risk assessment. Water Research 47:2050-64.

Gonzalez-Rey, M., and M. J. Bebianno. 2013. Does selective serotonin reuptake inhibitor (SSRI) fluoxetine affects mussel Mytilus galloprovincialis? Environmental Pollution 173:200-209.

Gu, Q., D. Ph, C. F. Dillon, V. L. Burt, and M. Sc. 2010. Prescription drug use continues to increase: U.S. prescription drug data for $2007-2008$. http://www.cdc.gov/nchs/products/databriefs/db42.htm. Retrieved December 7, 2016.

Guo, J. 2015. Impact of pharmaceuticals on algal species. Jiahua Guo University of York Environment December 2015.

Guo, J., A. Boxall, and K. Selby. 2015. Do pharmaceuticals pose a threat to primary producers? Critical Reviews in Environmental Science and Technology:00-00.

Gust, M., M. Gélinas, M. Fortier, M. Fournier, and F. Gagné. 2012. In vitro immunotoxicity of environmentally representative antibiotics to the freshwater 
mussel Elliptio complanata. Environmental Pollution 169:50-58.

Halling-Sørensen, B. 2000. Algal toxicity of antibacterial agents used in intensive farming. Chemosphere 40:731-739.

Halling-Sørensen, B., P. F. Nielsen, S Nors, F. I. Lanzky, H. C. H. Lützhøft, and S. E. Jørgensen. 1998. Occurrence, fate and effects of pharmaceutical substances in the environment- A review. Chemosphere 36:357-393.

Huang, D.-J., J.-H. Hou, T.-F. Kuo, and H.-T. Lai. 2014. Toxicity of the veterinary sulfonamide antibiotic sulfamonomethoxine to five aquatic organisms. Environmental Toxicology and Pharmacology 38:874-80.

Isidori, M., M. Lavorgna, A. Nardelli, L. Pascarella, and A. Parrella. 2005. Toxic and genotoxic evaluation of six antibiotics on non-target organisms. The Science of the total environment 346:87-98.

Ji, J. Y., Y. J. Xing, Z. T. Ma, J. Cai, P. Zheng, and H. F. Lu. 2013. Toxicity assessment of anaerobic digestion intermediates and antibiotics in pharmaceutical wastewater by luminescent bacterium. Journal of Hazardous Materials 246-247:319-323.

Kim, J., J. Park, P. G. Kim, C. Lee, K. Choi, and K. Choi. 2010. Implication of global environmental changes on chemical toxicity-effect of water temperature, $\mathrm{pH}$, and ultraviolet B irradiation on acute toxicity of several pharmaceuticals in Daphnia magna. Ecotoxicology 19:662-669.

Kümmerer, K. 2004. Resistance in the environment. The Journal of Antimicrobial Chemotherapy 54:311-20.

Kümmerer, K. 2008. Pharmaceuticals in the environment: sources, fate, effects and risks. Springer Science \& Business Media. 
Lacaze, E., J. Pédelucq, M. Fortier, P. Brousseau, M. Auffret, H. Budzinski, and M. Fournier. 2015. Genotoxic and immunotoxic potential effects of selected psychotropic drugs and antibiotics on blue mussel (Mytilus edulis) hemocytes. Environmental Pollution 202:177-86.

Lai, H.-T., J.-H. Hou, C.-I. Su, and C.-L. Chen. 2009. Effects of chloramphenicol, florfenicol, and thiamphenicol on growth of algae Chlorella pyrenoidosa, Isochrysis galbana, and Tetraselmis chui. Ecotoxicology and Environmental Safety 72:329-34.

Láng, J., and L. Köhidai. 2012. Effects of the aquatic contaminant human pharmaceuticals and their mixtures on the proliferation and migratory responses of the bioindicator freshwater ciliate Tetrahymena. Chemosphere 89:592-601.

Larcher, S., and V. Yargeau. 2012. Biodegradation of sulfamethoxazole: Current knowledge and perspectives. Applied Microbiology and Biotechnology 96:309-318.

Larson, J. H., N. L. Eckert, and M. R. Bartsch. 2014. Intrinsic variability in shell and soft tissue growth of the Freshwater mussel Lampsilis siliquoidea. PLoS ONE 9:1-7.

Lawrence, M. A. 2015. Package 'ez.' CRAN. Retrieved March 1, 2016. https://cran.rproject.org/web/packages/ez/ez.pdf.

Liu, Y., B. Gao, Q. Yue, Y. Guan, Y. Wang, and L. Huang. 2012. Influences of two antibiotic contaminants on the production, release and toxicity of microcystins. Ecotoxicology and Environmental Safety 77:79-87.

McCormick, P. V., and J. Cairns Jr. 1994. Algae as indicators of environmental change. Journal of Applied Phycology 6.5:509-526.

McEneff, G., L. Barron, B. Kelleher, B. Paull, and B. Quinn. 2014. A year-long study of the spatial occurrence and relative distribution of pharmaceutical residues in sewage 
effluent, receiving marine waters and marine bivalves. Science of The Total Environment 476-477:317-326.

Monteiro, S. C., and A. B. a Boxall. 2009. Factors affecting the degradation of pharmaceuticals in agricultural soils. Environmental toxicology and chemistry / SETAC 28:2546-2554.

National Center for Health Statistics. 2015. Health, United States, 2015.

Nie, X.-P., B.-Y. Liu, H.-J. Yu, W.-Q. Liu, and Y.-F. Yang. 2013. Toxic effects of erythromycin, ciprofloxacin and sulfamethoxazole exposure to the antioxidant system in Pseudokirchneriella subcapitata. Environmental Pollution 172:23-32.

Nord, C. E., T. Wadström, and B. Wretlind. 1974. Synergistic effect of combinations of sulfamethoxazole, trimethoprim, and colistin against Pseudomonas maltophilia and Pseudomonas cepacia. Antimicrobial Agents and Chemotherapy 6:521-523.

Oregon Department of Environmental Quality. 2016. Pharmaceuticals. http://www.deq.state.or.us/lq/sw/hhw/pharmaceuticals.htm.. Retrieved May 1, 2016.

Paine, R. T. 1966. Food Web Complexity and Species Diversity. The American Naturalist 100:65-75.

Price, N. M., G. I. Harrison, J. G. Hering, R. J. Hudson, P. M. V. Nirel, B. Palenik, and F. M. M. Morel. 1989. Preparation and Chemistry of the Artificial Algal Culture Medium Aquil. Biological Oceanography 6:443-461.

Rebolloso-Fuentes, M. M., A. Navarro-Pérez, F. García-Camacho, J. J. Ramos-Miras, and J. L. Guil-Guerrero. 2001. Biomass nutrient profiles of the microalga Nannochloropsis. Journal of Agricultural and Food Chemistry 49:2966-2972.

R Development Core Team (2008). R: A language and environment for statistical 
computing. R Foundation for Statistical Computing, Vienna, Austria. ISBN 3900051-07-0, URL http://www.R-project.org.

Richardson, B. J., P. K. S. Lam, and M. Martin. 2005. Emerging chemicals of concern: Pharmaceuticals and personal care products (PPCPs) in Asia, with particular reference to Southern China. Marine Pollution Bulletin 50:913-920.

Schiedek, D., K. Broeg, J. Barsiene, K. K. Lehtonen, J. Gercken, S. Pfeifer, H. Vuontisjärvi, P. J. Vuorinen, V. Dedonyte, A. Koehler, L. Balk, and R. Schneider. 2006. Biomarker responses as indication of contaminant effects in blue mussel (Mytilus edulis) and female eelpout (Zoarces viviparus) from the southwestern Baltic Sea. Marine Pollution Bulletin 53:387-405.

Schreiber, F., and U. Szewzyk. 2008. Environmentally relevant concentrations of pharmaceuticals influence the initial adhesion of bacteria. Aquatic Toxicology 87:227-233.

Simionato, D., M. A. Block, N. La Rocca, J. Jouhet, E. Maréchal, G. Finazzi, and T. Morosinotto. 2013. The response of Nannochloropsis gaditana to nitrogen starvation includes de novo biosynthesis of triacylglycerols, a decrease of chloroplast galactolipids, and reorganization of the photosynthetic apparatus. Eukaryotic Cell 12:665-676.

Sirtori, C., A. Aguera, W. Gernjak, and S. Malato. 2010. Effect of water-matrix composition on Trimethoprim solar photodegradation kinetics and pathways. Water Research 44:2735-2744.

Spolaore, P., C. Joannis-Cassan, E. Duran, and A. Isambert. 2006. Commercial applications of microalgae. Journal of Bioscience and Bioenginering 101:87-96. 
Suchanek, T. H. 1981. The role of disturbance in the evolution of life history strategies in the intertidal mussels. Oecologia 50:143-152.

Suchanek, T. H. 1992. Extreme biodiversity in the marine-environment-mussel bed communities of Mytilus-californianus. Environmental Journal 8:150-152.

Trovó, A. G., R. F. P. Nogueira, A. Agüera, A. R. Fernandez-Alba, C. Sirtori, and S. Malato. 2009a. Degradation of sulfamethoxazole in water by solar photo-Fenton. Chemical and toxicological evaluation. Water Research 43:3922-3931.

Trovó, A. G., R. F. P. Nogueira, A. Aguera, C. Sirtori, and A. R. Fernandez-Alba. 2009 b. Photodegradation of sulfamethoxazole in various aqueous media: Persistence, toxicity and photoproducts assessment. Chemosphere 77:1292-1298.

Tsiaka, P., V. Tsarpali, I. Ntaikou, M. N. Kostopoulou, G. Lyberatos, and S. Dailianis. 2013. Carbamazepine-mediated pro-oxidant effects on the unicellular marine algal species Dunaliella tertiolecta and the hemocytes of mussel Mytilus galloprovincialis. Ecotoxicology 22:1208-1220.

U.S. Food and Drug Administration. 2016. How to dispose of unused medicines. http://www.fda.gov/ForConsumers/ConsumerUpdates/ucm101653.htm. Retrieved May 1, 2016.

U.S. Food and Drug Administration (FDA). 2016. Medicines recommended for disposal by flushing listed by medicine and active ingredient. http://www.fda.gov/Drugs/ResourcesForYou/Consumers/BuyingUsingMedicineSafe ly/EnsuringSafeUseofMedicine/SafeDisposalofMedicines/ucm186187.htm. Retrieved May 1, 2016.

Vannini, C., G. Domingo, M. Marsoni, F. De Mattia, M. Labra, S. Castiglioni, and M. 
Bracale. 2011. Effects of a complex mixture of therapeutic drugs on unicellular algae Pseudokirchneriella subcapitata. Aquatic Toxicology (Amsterdam, Netherlands) 101:459-65.

Waycott, M., C. M. Duarte, T. J. B. Carruthers, R. J. Orth, W. C. Dennison, S. Olyarnik, A. Calladine, J. W. Fourqurean, K. L. Heck, Ar. Hughes, G. A. Kendrick, Wj. Kenworthy, F. T. Short, and S. L. Williams. 2009. Accelerating loss of seagrasses across the globe threatens coastal ecosystems. Proceedings of the National Academy of Sciences, USA 106:12377-12381.

WHO (World Health Organization). 2015. WHO Model List of Essential Medicines. http://www.who.int/medicines/publications/essentialmedicines/EML2015_8-May15.pdf. Retrieved December 6, 2015.

WHO (World Health Organization). 1998. Antimicrobial Resistance. Fact Sheet no. 194. Available: http://www.who.int/mediacentre/factsheets/fs194/en/. Retrieved December 6, 2015.

WHO (World Health Organization). 2016. Pharmaceutical Industry. http://www.who.int/intellectualproperty/news/en/Submission5.pdf. Retrieved March 13, 2016. 